\title{
Effect of different parameters controlling the flexural behavior of RC beams strengthened with NSM using nonlinear finite element analysis
}

\author{
Ramy Reda \\ Higher Technological Institute, Egypt \\ ramy_mostafa12000@yahoo.com, bttp://orcid.org/0000-0002-3298-7925 \\ Zeinab Omar, Hossam Sallam, Seleem S. E. Ahmad \\ Zagarig University, Egypt \\ zomar73@yahoo.com,http://orcid.org/0000-0002-5531-9014 \\ hem_sallam@yahoo.com, bttp://orcid.org/0000-0001-9217-9957 \\ seleemahmad62@yahoo.com, bttp:/ /orcid.org/0000-0001-9894-0209
}

\begin{abstract}
Near surface mounted technique become the most attractive technique for strengthening RC structures. A lot of research had been conducted to study experimentally the flexural behavior of RC members strengthened with NSM technique unlike the numerical research. A numerical investigation utilizes the non-linear finite element (FE) modeling using ANSYS was performed. The developed FE model considers the behavior of the epoxy-concrete interface using cohesive zone model (CZM) which is capable of predicting the failure mode of the strengthened beams. The parametric study include the effect of different parameters such as NSM bar number, NSM bar length, end inclination angle and end inclination leg length on the flexural behavior of strengthened beams. The results showed that, The developed FE model able to predict the expected modes of failure in NSM technique, the NSM bar length was effective till 0.5 of beam span, beams strengthened with end inclined angle $45^{\circ}$ NSM bar gives the highest improvement in load carrying capacity, this improvement was very close in case of using end inclined angle of $60^{\circ}$ and $90^{\circ}$.
\end{abstract}

KEYWORDS. Finite Element Modeling; Near Surface Mounted; Debonding; End Anchorage; Inclination Angle; Flexural Strengthening.

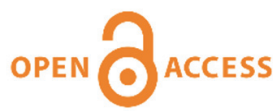

Citation: Reda, R.M., Zeinab, O., Sallam, H.E.M, Seleem S. E. Ahmad, Effect of different parameters controlling the flexural behavior of RC beams strengthened with NSM using nonlinear finite element analysis, Frattura ed Integrità Strutturale, 53 (2020) 106-123

Received: 21.03.2020

Accepted: 12.04 .2020

Published: 01.07.2020

Copyright: (C) 2020 This is an open access article under the terms of the CC-BY 4.0, which permits unrestricted use, distribution, and reproduction in any medium, provided the original author and source are credited.

\section{INTRODUCTION}

einforced concrete constructions are widely used over the world, after a while use it will deteriorates, demolition or rebuild will lead to bleeding the time and cost. In the last decade several techniques were conducted by many researchers to repair and strengthen the RC structures such as near surface mounted (NSM) and externally bonded 
(EB) [1-7]. NSM is more effective than EB due to increasing the flexural strength for RC structures over EB by increasing bond capacity due to larger bonded surface area, furthermore it needs less installation time and makes protection against external damage by embedding the FRP bars in the concrete cover [8-10]. In NSM technique grooves are cut in the concrete cover and half of the groove filled with the adhesive, FRP bars inserted into the groove, the remaining half of the adhesive filled in the groove and leveled [7]. NSM technique has a better bond performance compared to EB, the two interfaces of NSM (concrete-adhesive, adhesive-FRP) are affected by FRP properties, FRP bar length, bar diameter, FRP bar surface treatment, groove geometry, groove size and concrete properties [11,12]. Several investigations were performed to study the flexural behavior of RC beams strengthened with NSM FRP reinforcement. Hassan et al. [13] studied the effect of CFRP bar length, groove width and the strength of concrete on the flexural behavior of concrete structures, the results suggested that the NSM CFRP bars length should not be less than 80 times the diameter of the used bars and the resistance of concrete split failure increased by the increasing of the groove width and/or using high strength concrete.

Al-Mahmoud et al. [14] studied the effect of using two different diameter of CFRP bars; 6 and 12mm, type of concrete conventional or high-strength concrete and two types of filling materials (resin and mortar) on the flexural behavior. The results concluded that using CFRP bars with $12 \mathrm{~mm}$ diameter increase the carrying load capacity by $83.6 \%$ compared with beams strengthened with $6 \mathrm{~mm}$ bar diameter, on the other hand the concrete strength doesn't effect on the load carrying capacity if the failure of the strengthened beams are due to NSM system failure, also the failure mode can be changed by the type of adhesive used.

Finite element analysis either by ANSYS or ABAQUS software showed that it is a good solution in different structures problems [15-17]. Hawileh [18] developed 3D nonlinear FE ANSYS model to predict the load carrying capacity of RC beams strengthened with NSM FRP bars and validate this model by comparing the predicted results with the experimental results obtained by Al-Mahmoud et al. [14]. Then study the effect of using different types of FRP bars materials such as CFRP, AFRP and GFRP and CFRP bar diameter. The results showed very good agreement between the ANSYS model and the experimental results, all types of FRP bars enhance the flexural strength especially CFRP which increase the strength by $18.5 \%$ and $43.8 \%$ compared to AFRP and GFRP bars, respectively. Furthermore the increasing of the FRP diameter has a significantly effect on load carrying capacity of the strengthened RC beams [18].

Reda et al. [8] studied the effect of GFRP bar length on the flexural strength of RC beams, The beam strengthened with GFRP bar length 1000,1200, 1400 and 1800mm, and also studied different epoxy length effect and end anchorage using GFRP bars with bent end inclined by $45^{\circ}$ and $90^{\circ}$ and others straight on the flexural strength of RC beams. The author concluded that the beam strengthened with GFRP bars of length $1400 \mathrm{~mm}$ gives the higher load carrying capacity, the results showed that either the beams strengthened with bent end GFRP bars inclined by $45^{\circ}$ showed superior flexural behavior over the beams strengthened with bent end GFRP bars inclined by $90^{\circ}$ or straight bars. On the other hand a little effect of partial bonded in the constant moment region on the flexural behavior of strengthened beam. EL-Emam et al. [19] studied experimentally and numerically the effect of NSM GFRP bars length, area of main steel reinforcement and the thickness of the concrete cover on the flexural response of strengthened RC beams, the author used different GFRP bars length; 550, 1150 and $1800 \mathrm{~mm}$, also used $30 \mathrm{~mm}$ and $50 \mathrm{~mm}$ concrete cover. The results showed that increasing of GFRP bar length increase the flexural strength, the same observation when increasing the main steel reinforcement ratio from $2-\varnothing 10 \mathrm{~mm}$ to $2-\varnothing 16 \mathrm{~mm}$ the ultimate load will be increased, the opposite observation when increasing the concrete cover thickness the flexural capacity will be decreased, the numerical results showed a good agreement with the experimental results [19].

Sharaky et al. [20] studied the effect of NSM strengthening location, NSM strengthening pattern, NSM FRP strips number and of the groove depth on the flexural behavior strengthened RC beams. Two different location of NSM strengthening, near the bottom surface of the beams and beneath the stirrups, the results showed that a significantly enhancement on the ultimate load of the strengthened beams in case of installing the NSM strengthening beneath the stirrups compared with installing the NSM strengthening near the bottom surface of the beam, furthermore using two NSM FRP strips installed in one slot beneath the stirrups increase the load carrying capacity by $187 \%$ if compared with control beam. Also the groove depth gives a noticeable effect.

Although a lot of research had been carried out to study the flexural behavior of RC members strengthened with NSM technique experimentally, further numerical researches are still required to understand the effect of several parameters on the flexural behavior of RC members. In this paper the effect of many parameters such as NSM bar number, NSM bar length, end inclination angle and end inclination leg length on the flexural behavior of strengthened beams with NSM technique were studied numerically using non-linear finite element FE modeling. The numerical FE model was compared with experimental results conducted from another research [8]. 


\section{FINITE ELEMENT FE MODEL}

$\mathrm{N}$ on-linear finite element FE using (ANSYS -Version 19.0) was performed to study the flexural behavior of RC beams strengthened with NSM technique [21]. First the present model was verified by comparing the model with the experimental results conducted by Reda et al. [8]. After validation, a parametric study was conducted.

\section{Elements Description}

ANSYS element library includes several elements which can be used to simulate the different types of materials [21]. In this research (SOLID65) was used to simulate concrete and epoxy adhesive, (SOLID65) has eight nodes with three degrees of freedom at each node - translations in the nodal $\mathrm{x}, \mathrm{y}$, and $\mathrm{z}$ directions. SOLID65 has the ability to crack in tension and crush in compression. The Willam and Warnke criterion was used to define the failure of concrete [15, 22], it is the available model in ANSYS material library to model concrete [15]. A (LINK180) element was used to model the steel reinforcement and NSM FRP bars. Two nodes are required for this element. Each node has three degrees of freedom, - translations in the nodal $\mathrm{x}, \mathrm{y}$, and $\mathrm{z}$ directions. The element is also capable of plastic deformation. An eight-node solid element (SOLID45) was used for the steel plates (Loading or supports) in the models. The element is defined with eight nodes having three degrees of freedom at each node-translations in the nodal $\mathrm{x}, \mathrm{y}$, and $\mathrm{z}$ directions [21].

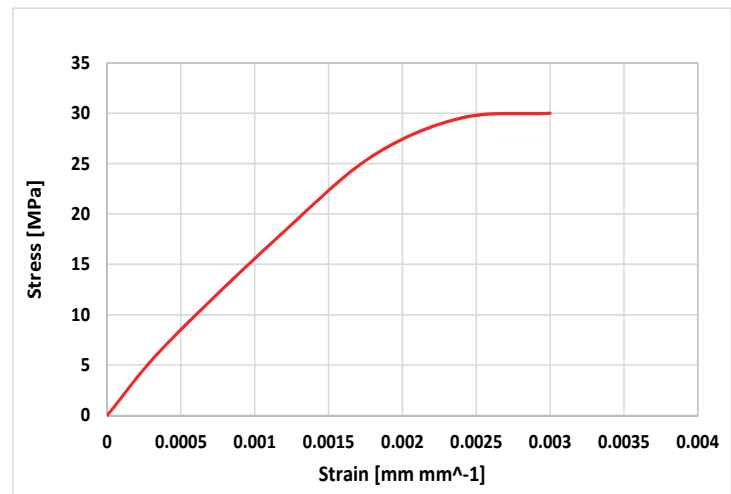

(a) Concrete in compression

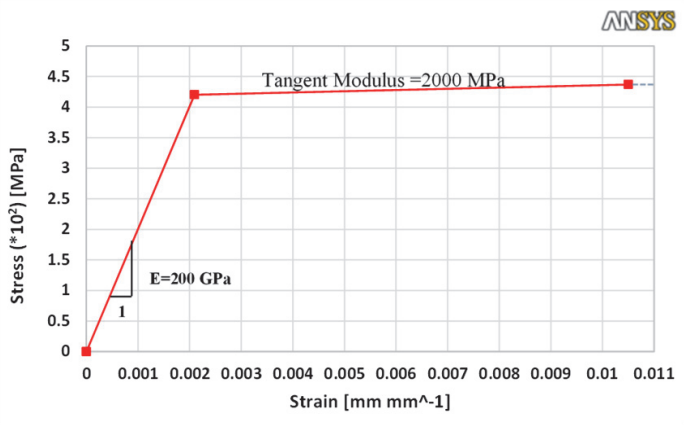

(c) Steel

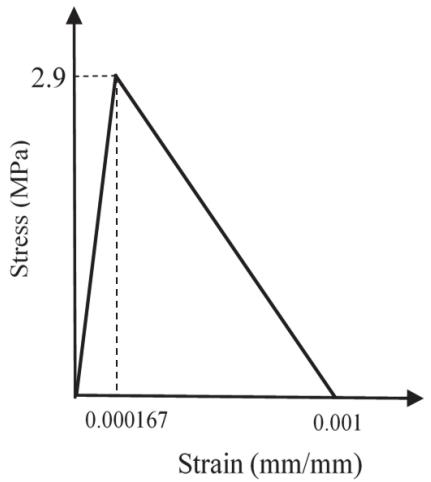

(b) Concrete in tension [22]

Figure 1: The stress strain curves used in model; concrete, steel and GFRP.

\section{Materials Modeling}

Concrete, steel and GFRP stress strain curves used in model are shown in (Fig.1). (Fig. 1-a) defined the concrete as a material with a nonlinear behavior with a compressive strength, tensile strength, elastic modulus and Poisson's ratio of $30 \mathrm{MPa}$ and 2.9 $\mathrm{MPa}, 20 \mathrm{GPa}$ and 0.2 respectively, open and closed crack shear coefficients were taken as 0.4 and 0.8 respectively, $\left(\varepsilon_{0}\right.$ is the strain at the ultimate compressive strength $=2 f_{\mathrm{c}}^{\prime} / E_{\mathrm{c}}$ and; $E_{\mathrm{c}}$ is the concrete elastic modulus [23]). (Fig. 1-d) shows the concrete behavior in tension simulated by smeared crack approach. Smeared crack approach has been adopted to define the concrete behavior in tension. The smeared crack approach was discussed previously by the authors [24]. The steel reinforcement was assumed to have an elastic-perfectly plastic response, (Fig. 1-c) shows the elastic-strain hardening behavior for the reinforcing steel bars with yield stress, elastic modulus and Poisson's ratio of $420 \mathrm{MPa}, 200 \mathrm{GPa}$ and 0.3 respectively. The NSM GFRP bars were considered to be linear elastic up to failure, (Fig. 1-d), with tensile strength, elastic 
modulus and Poisson's ratio of $820 \mathrm{MPa}, 44.8 \mathrm{GPa}$ and 0.26 respectively. The material used to model concrete was also used to define the adhesive behavior with tensile strength, elastic modulus and Poisson's ratio of 24.8 MPa, 4.48 GPa and 0.37 respectively. While the steel plates (loading or supports) were modeled as rigid elastic material having a modulus of elasticity and Poisson's ratio of $200 \mathrm{GPa}$ and 0.3 respectively.

\section{Concrete-Epoxy Interface}

The epoxy-concrete interface was defined by two element types (CONTA174 and TARGE170) which can be used for pairbased contact, element type TARGE170 was used to model the target surface (concrete), while the element type (CONTA173) was used to model the contact surface (epoxy). CONTA174 is applicable to 3-D structural and coupled-field contact analyses, the element is used to represent contact and sliding between 3-D target surfaces and a deformable surface defined by this element. On the other hand TARGE170 is capable to represent various 3D target surfaces for the associated contact elements [21, 25 and 26]. Mixed-mode debonding based on normal tension stress-gap and shear stress-slip was assigned to the contact surface by developing the CZM in ANSYS menu [25, 26]. The maximum normal contact stress (Eqn. (1) [26]) and the contact gap at the completion of debonding (Eqn. (2) [26]) used to the tension stress-gap model were $3.28 \mathrm{MPa}$ and $0.045 \mathrm{~mm}$ respectively.

$$
\begin{aligned}
& \sigma_{\max }=0.6 \sqrt{f_{c}^{\prime}}(\mathrm{MPa}) \\
& u_{\mathrm{n}}^{\mathrm{c}_{\mathrm{n}}}=G_{f_{0}}\left(\frac{\sqrt{10} f_{i}}{24.3}\right)^{0.2}(\mathrm{~mm})
\end{aligned}
$$

where is the $\sigma_{\max }$ is the maximum normal contact stress, $f c^{\prime}$ the concrete compressive strength, $u_{\mathrm{n}}$ is the contact gap at the completion of debonding and $G_{f o}$ is the base value of fracture energy which depends on the maximum aggregate size and equal $0.03475 \mathrm{~N} / \mathrm{mm}$ as reported in CEB-FIP Model Code [27].

For the shear stress-slip model, the maximum equivalent tangent contact stress and tangential slip at the completion of debonding were 6.74 MPa and $1.086 \mathrm{~mm}$ respectively, as calculated Using Eqs. (3)-(5) [26].

$$
\begin{aligned}
& \tau_{\max }=(0.802+0.078 \varphi) f c^{\prime 0.6}(\mathrm{MPa}) \\
& u_{\mathrm{c}_{\mathrm{t}}}=\frac{0.976 \varphi^{0.526}}{0.802+0.078 \varphi}(\mathrm{mm}) \\
& \varphi=\frac{\text { Groove depth }+1 \mathrm{~mm}}{\text { Groove width }+2 \mathrm{~mm}}(\mathrm{~mm} / \mathrm{mm})
\end{aligned}
$$

where $\tau_{\max }$ is the maximum shear contact stress, $\varphi$ the aspect ratio of the interface failure plane, $f c^{\prime}$ the concrete compressive strength, and $u^{c}$ the contact slip at the completion of debonding [26].

\section{Model Geometry}

The same geometry, dimensions, material properties and boundary conditions for all simulated beams. Concrete beam, boundary conditions and meshing of the FE model for CB, beam 2G-0.8/S and beam 2G-0.5-60/100 as an example were shown in (Fig. 2). Furthermore two rigid steel supports and loading plates were also modeled to transfer the applied loads and reduce the stress concentration if the loads are applied directly to the concrete elements. Sensitivity analysis was performed by studying the effect of element size 15, 20, 25 and $30 \mathrm{~mm}$ on the results of the numerical model for CB compared to the experimental results [8] as shown in (Fig. 3), from the comparisons the mesh element size 20 mm was more suitable to use to model all beams, and was used for all elements; concrete, steel, NSM bars, adhesive (epoxy) and steel plates (loading and supports). 


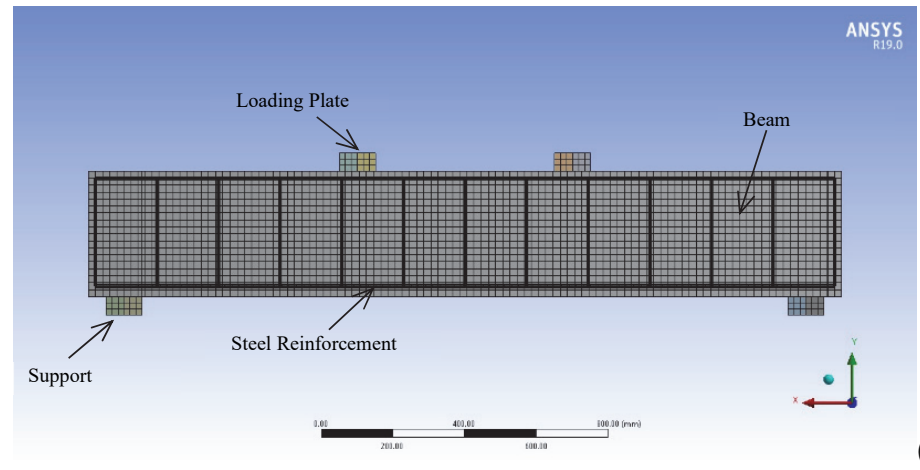

(a)

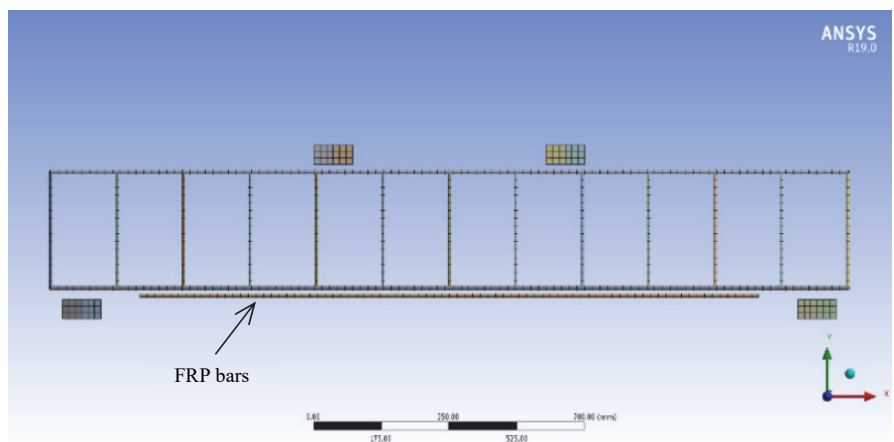

(b)
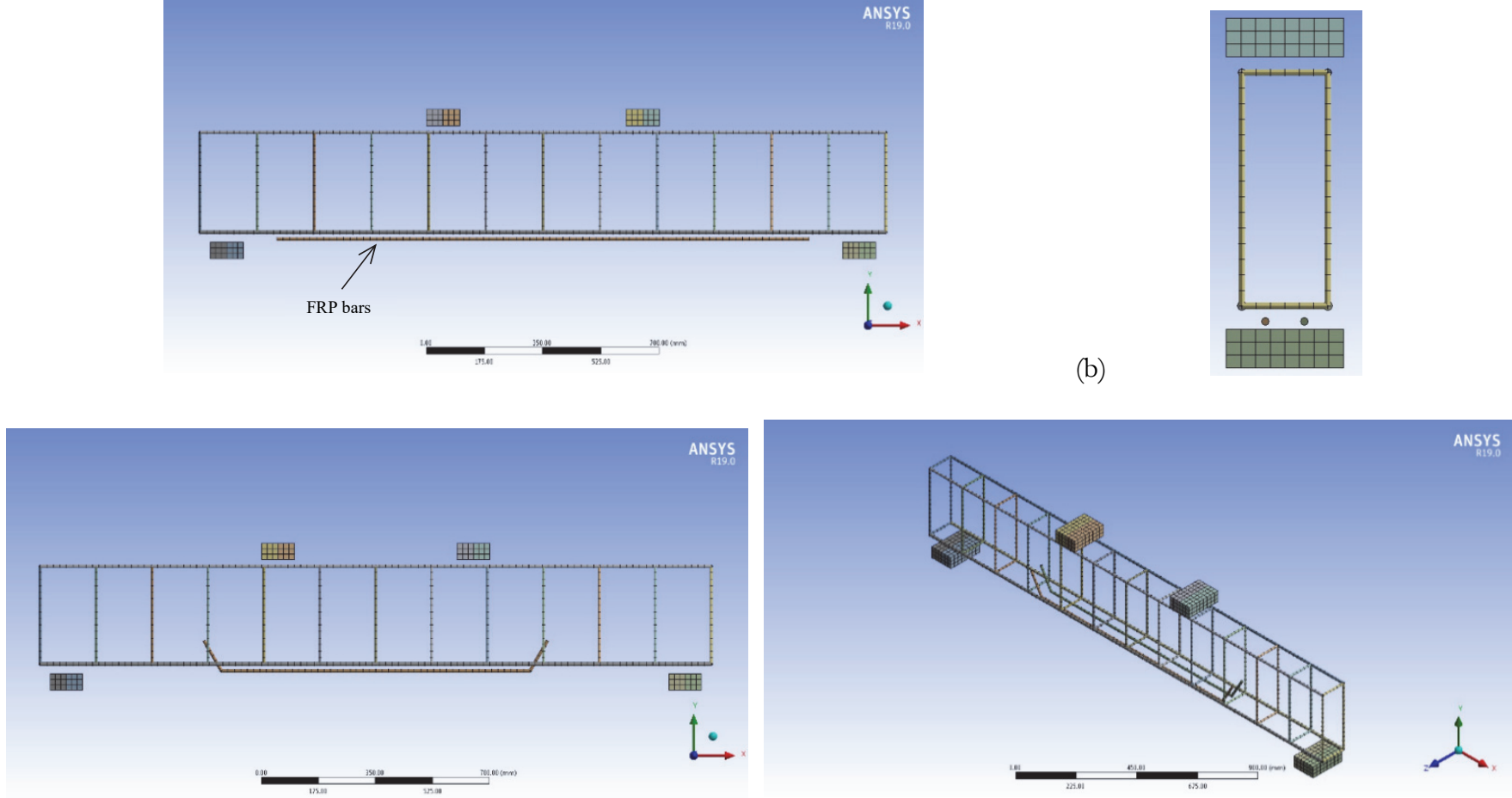

(c)

Figure 2: The simulated beams: (a) CB beam, (b) generated mesh for 2G-0.8/S beam and its cross section, (c) generated mesh for 2G0.5-60/100 beam.
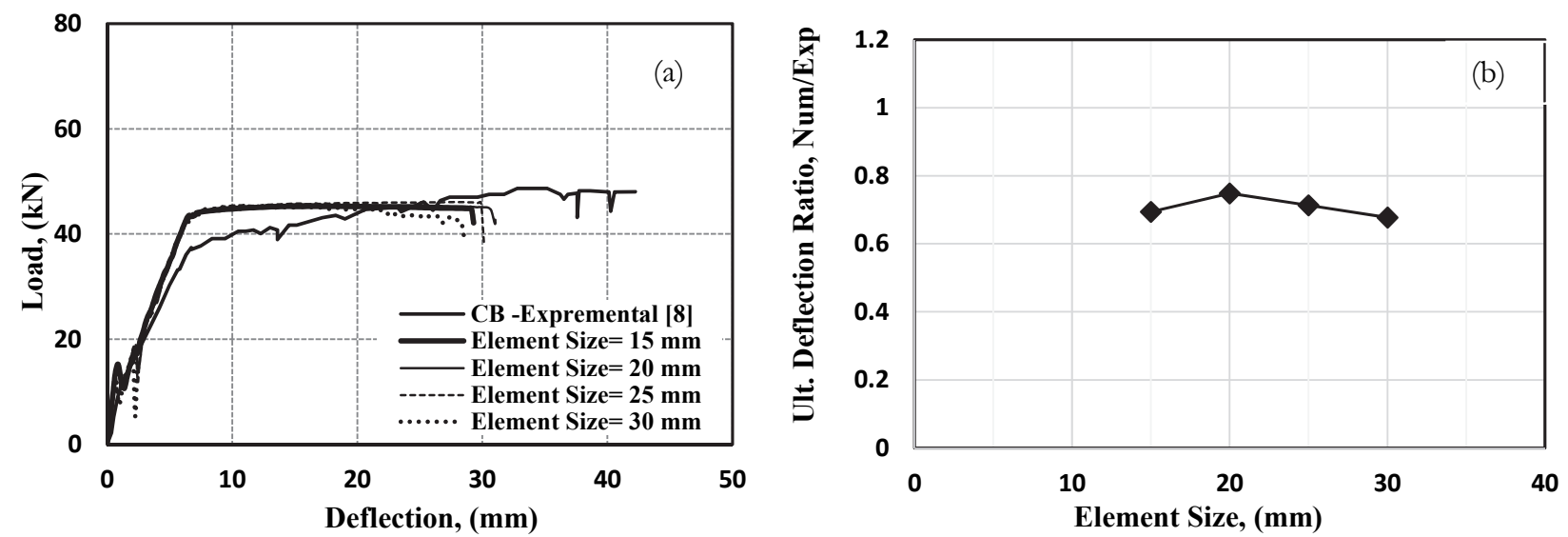

Figure 3: The effect of element size on the sensitivity of the CB model: (a) Load deflection curve, (b) Maximum deflection. 
Parametric Study

The Non-linear finite element models were extended to investigate the effect of various parameters on the flexural behavior of NSM FRP strengthened beams such as; NSM bar numbers, NSM bar length, end anchorage inclination angle and end anchorage inclination length. All beams had a total length of $2200 \mathrm{~mm}$ and a rectangular cross-section having a width of $150 \mathrm{~mm}$ and depth of $350 \mathrm{~mm}$. The beams reinforcement consisted of two $12 \mathrm{~mm}$ diameter bars for bottom reinforcement and two $10 \mathrm{~mm}$ diameter bars for top reinforcement. As well as $8 \mathrm{~mm}$ diameter steel stirrups were placed at a distance of $200 \mathrm{~mm}$. The beam details; full dimensions, reinforcement arrangements, the loading configuration and the groove locations of the modified beams were shown in (Fig. 4). The modified beams consists of one un-strengthened beam (control beam $\mathrm{CB}$ ), and 63 strengthened beams. All beams were tested under two point loading flexural tests. The FE models were conducted to investigate the effect of various parameters on the flexural behavior of the NSM strengthened beams. Full details of the parametric study of the models are listed in (Fig. 5), Tab. 1 and explained below.

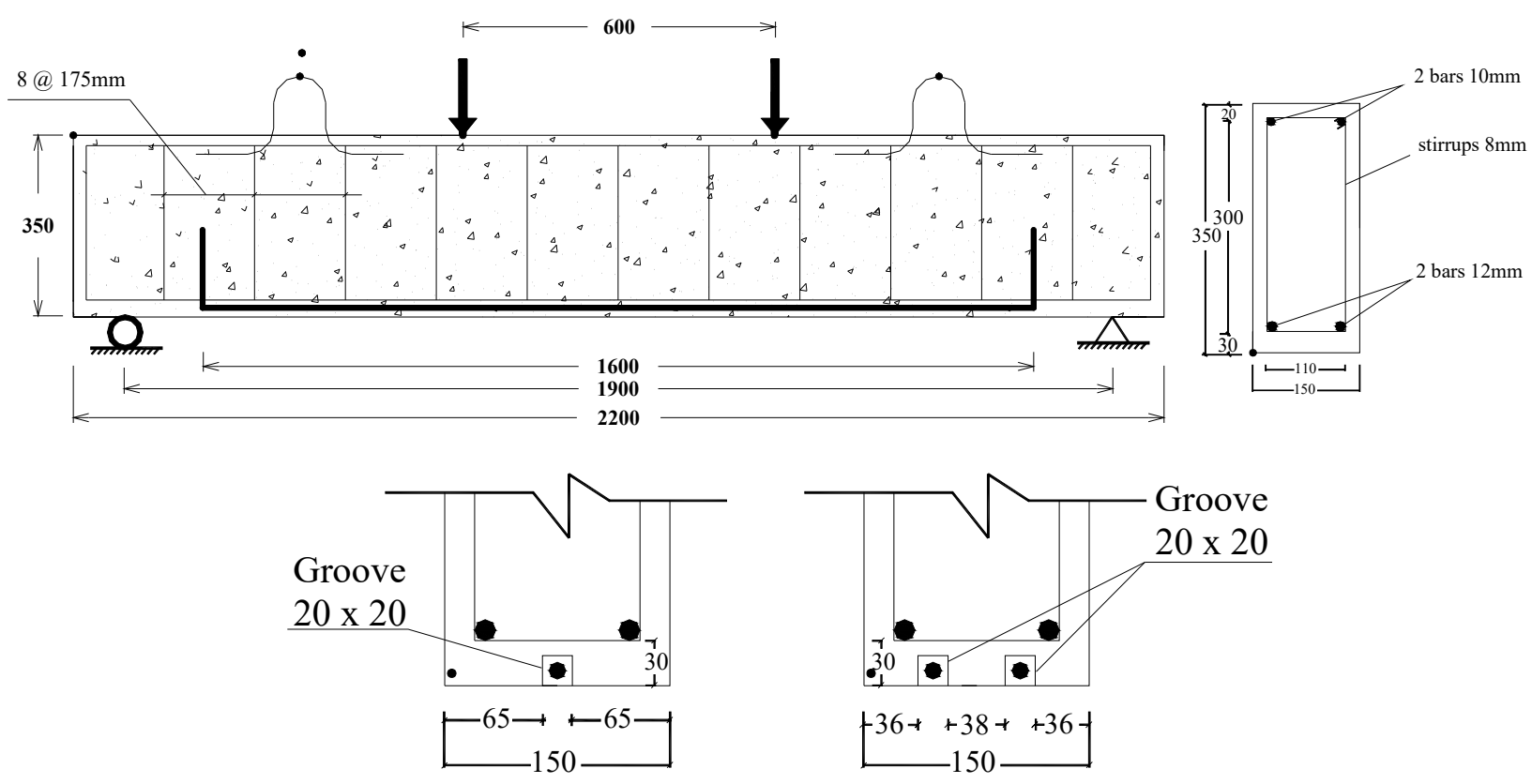

Figure 4: Beam details and grooves locations.

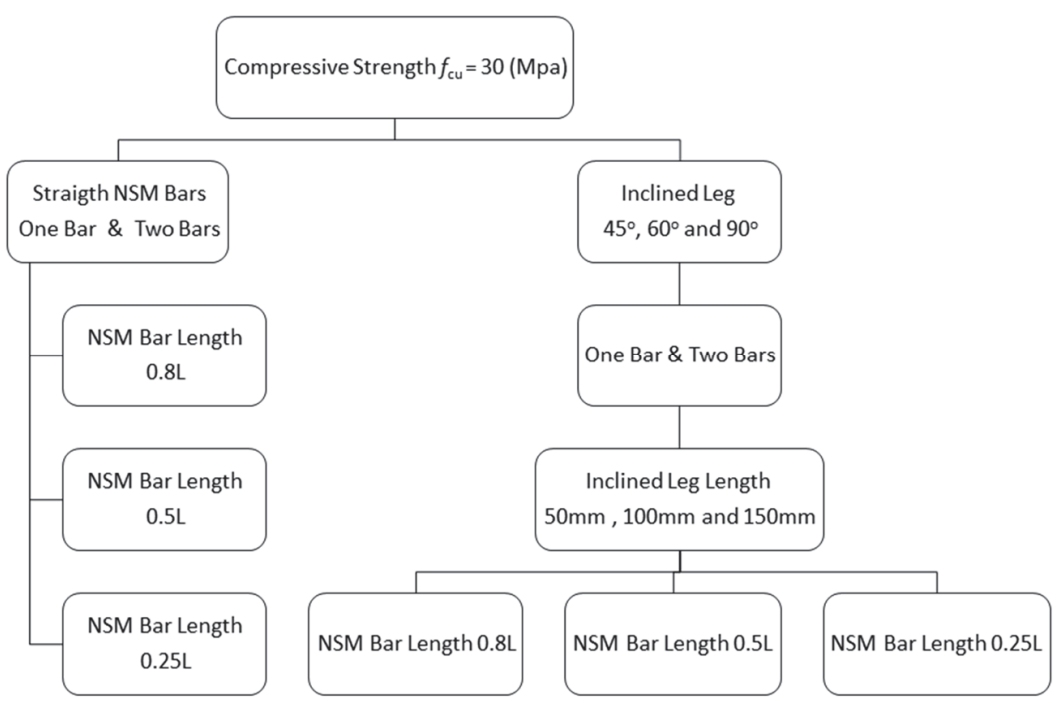

Figure 5: Full details of the parametric study of the models. 
The strengthened beams were divided into four groups according to end anchorage inclination angle; S (straight without inclined leg), $45^{\circ}, 60^{\circ}$ and $90^{\circ}$. The first group contains six beams, the first beam was strengthened with one straight NSM bar of length $1600 \mathrm{~mm}$, the second beam was strengthened with one straight NSM bar of length 1000mm and the third beam was strengthened with one straight NSM bar of length $500 \mathrm{~mm}$. The remaining three beams are similar to the above beams but with two straight NSM bars. The three remaining groups having inclined leg, each group divided to subgroups according to the inclined leg length $(50,100$ and $150 \mathrm{~mm})$. Second group consisted of eighteen beam divided into three subgroups as mention. First subgroup contain six beams, the first beam was strengthened with one NSM bar of length $1600 \mathrm{~mm}$ with end inclined angle $45^{\circ}$ and end inclined leg $50 \mathrm{~mm}$ in length, the second beam was strengthened with one NSM bar of length $1000 \mathrm{~mm}$ with end inclined angle $45^{\circ}$ and end inclined leg $50 \mathrm{~mm}$ in length, the third beam was strengthened with one NSM bar of length $500 \mathrm{~mm}$ with end inclined angle $45^{\circ}$ and end inclined leg $50 \mathrm{~mm}$ in length, the remaining three beams with the same details but with two NSM bars. Second subgroup contain six beams with the same configuration of the first subgroup but with end anchorage inclination leg length of $100 \mathrm{~mm}$. Third subgroup contain six beams with the same configuration with end anchorage inclination leg length of $150 \mathrm{~mm}$. The third and fourth groups with end anchorage inclination angle of $60^{\circ}$ and $90^{\circ}$ respectively. Tab. 1 summarizes the configuration of the modified beams. The identifications are as follows: NG-L-I/Y where $\mathrm{N}$ is refers to no of NSM bars, G = GFRP NSM bars, L = length of NSM GFRP bar $(0.8=1600 \mathrm{~mm}, 0.5=1000 \mathrm{~mm}$ and $0.25=500 \mathrm{~mm})$, $\mathrm{I}$ is the inclination angle of the end anchorage $(\mathrm{S}=$ no leg, $45^{\circ}, 60^{\circ}$ and $90^{\circ}$ ) and $\mathrm{Y}$ is refers to end anchorage inclination length; 50,100 and $150 \mathrm{~mm}$.

\section{VALIDATION OF THE FE MODELS}

A comparison between the modified model and experimental results; load deflection curve and mode of failure produced by Reda et al. [8] for the control beam (CB) and (F2-180/90) beam are shown in (Fig. 6). The comparison showed a good agreement between the developed models and experimental results at all stages of loading and in mode of failure.
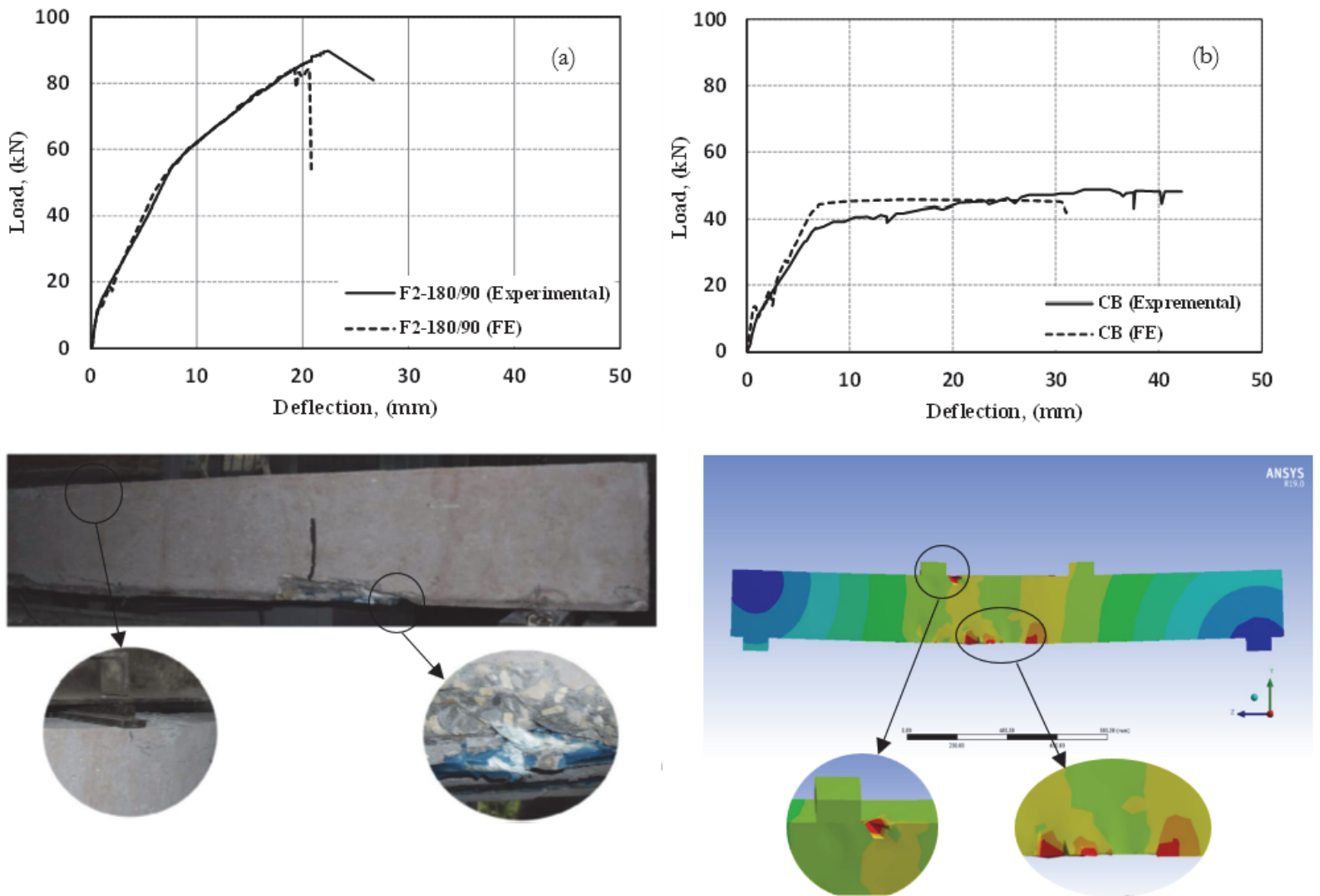

Figure 6: Comparison between experimental results presented in [8] and FE model: (a) load-deflection curve for CB, (b) loaddeflection curve of beam F2-180/90 and (c) failure mode of beam 2F-180/90 and the predicted from FE. 


\begin{tabular}{|c|c|c|c|c|c|}
\hline $\mathrm{CB}$ & - & - & - & - & Reference Beam \\
\hline $1 G-0.5-S$ & 1 & 1000 & Straight & - & NSM strengthening and NSM bar length \\
\hline $1 \mathrm{G}-0.25-\mathrm{S}$ & & 500 & & & NSM strengthening and NSM bar length \\
\hline $2 \mathrm{G}-0.8-\mathrm{S}$ & & 1600 & & & NSM strengthening and NSM bar number \\
\hline $1 G-0.5-45 / 50$ & & 1000 & & 50 & End anchorage and bar length \\
\hline $1 G-0.25-45 / 50$ & & 500 & & & End anchorage and bar length \\
\hline $1 G-0.8-45 / 100$ & & 1600 & & & End anchorage and leg length \\
\hline $1 G-0.5-45 / 100$ & 1 & 1000 & 45 & 100 & End anchorage, bar length and leg length \\
\hline $1 G-0.25-45 / 100$ & & 500 & & & End anchorage, bar length and leg length \\
\hline $1 G-0.8-45 / 150$ & & 1600 & & & End anchorage and leg length \\
\hline $2 G-0.8-45 / 100$ & & 1600 & & & End anchorage, bars no; and leg length \\
\hline $2 \mathrm{G}-0.5-45 / 100$ & 2 & 1000 & 45 & 100 & End anchorage, bars no; bar length and leg length \\
\hline $2 G-0.25-45 / 100$ & & 500 & & & End anchorage, bars no;, bar length and leg length \\
\hline $2 \mathrm{G}-0.8-45 / 150$ & & 1600 & & & End anchorage, bars no; and leg length \\
\hline $2 G-0.5-45 / 150$ & & 1000 & & 150 & End anchorage, bars no; bar length and leg length \\
\hline $2 \mathrm{G}-0.25-45 / 150$ & & 500 & & & End anchorage, bars no; bar length and leg length \\
\hline $1 \mathrm{G}-0.8-60 / 50$ & & 1600 & & & Leg inclination angle \\
\hline $1 G-0.5-60 / 50$ & & 1000 & & 50 & Inclination angle and bar length \\
\hline $1 \mathrm{G}-0.25-60 / 50$ & & 500 & & & Inclination angle and bar length \\
\hline $1 \mathrm{G}-0.8-60 / 100$ & & 1600 & & & Inclination angle and leg length \\
\hline $1 G-0.5-60 / 100$ & 1 & 1000 & 60 & 100 & Inclination angle, bar length and leg length \\
\hline $1 G-0.25-60 / 100$ & & 500 & & & Inclination angle, bar length and leg length \\
\hline $1 \mathrm{G}-0.8-60 / 150$ & & 1600 & & & Inclination angle and leg length \\
\hline $2 G-0.5-60 / 150$ & & 1000 & & 150 & Inclination angle, bars no; bar length and leg length \\
\hline $2 G-0.25-60 / 150$ & & 500 & & & Inclination angle, bars no; bar length and leg length \\
\hline $1 G-0.8-90 / 50$ & & 1600 & & & Leg inclination angle \\
\hline $1 G-0.5-90 / 50$ & & 1000 & & 50 & Inclination angle and bar length \\
\hline $1 G-0.25-90 / 50$ & & 500 & & & Inclination angle and bar length \\
\hline $1 G-0.8-90 / 100$ & & 1600 & & & Inclination angle and leg length \\
\hline $1 G-0.5-90 / 100$ & 1 & 1000 & 90 & 100 & Inclination angle, bar length and leg length \\
\hline $1 G-0.25-90 / 100$ & & 500 & & & Inclination angle, bar length and leg length \\
\hline $1 G-0.8-90 / 150$ & & 1600 & & & Inclination angle and leg length \\
\hline $1 G-0.5-90 / 150$ & & 1000 & & 150 & Inclination angle, bar length and leg length \\
\hline $1 G-0.25-90 / 150$ & & 500 & & & Inclination angle, bar length and leg length \\
\hline $2 \mathrm{G}-0.8-90 / 50$ & & 1600 & & & Inclination angle and bars no; \\
\hline $2 \mathrm{G}-0.5-90 / 50$ & & 1000 & & 50 & Inclination angle, bars no; and bar length \\
\hline $2 \mathrm{G}-0.25-90 / 50$ & & 500 & & & Inclination angle, bars no; and bar length \\
\hline $2 \mathrm{G}-0.8-90 / 100$ & & 1600 & & & Inclination angle, bars no; and leg length \\
\hline $2 G-0.5-90 / 100$ & 2 & 1000 & 90 & 100 & Inclination angle, bars no; bar length and leg length \\
\hline $2 G-0.25-90 / 100$ & & 500 & & & Inclination angle, bars no; bar length and leg length \\
\hline 2G-0.8-90/150 & & 1600 & & & Inclination angle, bars no; and leg length \\
\hline 2G-0.5-90/150 & & 1000 & & 150 & Inclination angle, bars no; bar length and leg length \\
\hline $2 G-0.25-90 / 150$ & & 500 & & & Inclination angle, bars no; bar length and leg length \\
\hline
\end{tabular}

Table 1: Details of the parametric study of the models. 


\section{RESULTS AND DISCUSSION}

$\mathrm{T}$ he key points of the load-deflection curves obtained from the FE analysis; such as cracking load $P_{\text {cr, }}$ yield load $P_{\mathrm{y}}$, yield deflection $\Delta_{\mathrm{y}}$ ultimate load $P_{\mathrm{u}}$ and maximum deflection $\Delta_{\mathrm{u}}$, percentage of increase in maximum load carrying capacity for strengthened beams with respect to $\mathrm{CB} P_{\mathrm{u}} \%$, in addition to ductility index $\mu$ (the ratio of the ultimate deflection to the deflection at yielding), stiffness $E$, energy absorption $\Omega$ (the area under load-deflection curve) and also failure mode of the strengthened beams were presented in Tab. 2. The control beam failed due to concrete crushing after yielding of the steel reinforcement, while beams $1 \mathrm{G}-0.25 / \mathrm{S}, 2 \mathrm{G}-0.5-45 / 150,2 \mathrm{G}-0.5-60 / 100$ and $2 \mathrm{G}-0.25-90 / 150$ for example failed due to epoxy debonding as shown in (Fig. 7) which mean that the developed FE model is capable of predicting the epoxy-concrete interface debonding failure.

\begin{tabular}{|c|c|c|c|c|c|c|c|c|c|c|}
\hline Beam ID & $\begin{array}{c}P_{c r} \\
(\mathrm{kN})\end{array}$ & $\begin{array}{c}P_{y} \\
(\mathrm{kN})\end{array}$ & $\begin{array}{c}\Delta_{y} \\
(\mathrm{~mm})\end{array}$ & $\begin{array}{c}P_{u} \\
(\mathrm{kN})\end{array}$ & $\begin{array}{c}\Delta_{\mathrm{u}} \\
(\mathrm{mm})\end{array}$ & $P_{u} \%$ & $\mu$ & $\begin{array}{c}E \\
(\mathrm{kN} / \mathrm{mm})\end{array}$ & $\begin{array}{c}\Omega \\
(\mathrm{kN} \cdot \mathrm{mm})\end{array}$ & Failure mode \\
\hline $\mathrm{CB}$ & 27.5 & 85 & 4.3 & 90.55 & 21 & - & 4.9 & 65.8 & 1706 & $\mathrm{CC}$ \\
\hline $1 G-0.8-S$ & 33 & 94 & 4.2 & 122.9 & 14.7 & 35.7 & 3.5 & 65.9 & 1403.1 & CCS \\
\hline $1 G-0.5-S$ & 32 & 92 & 4.2 & 119.7 & 11 & 32.2 & 2.6 & 65.9 & 953 & CCS \\
\hline $1 G-0.25-S$ & 28 & 91 & 4.5 & 94.7 & 30 & 4.6 & 6.7 & 66.0 & 2636.4 & EED-CCS \\
\hline $2 \mathrm{G}-0.8-\mathrm{S}$ & 32 & 106 & 4.5 & 154.1 & 13.6 & 70.2 & 3.0 & 66.1 & 1492.4 & $\mathrm{EC}$ \\
\hline $2 G-0.5-S$ & 33 & 105 & 4.6 & 129.9 & 10.1 & 43.5 & 2.2 & 66.2 & 941.9 & EED \\
\hline $2 \mathrm{G}-0.25-\mathrm{S}$ & 35.5 & 90 & 4.2 & 96.4 & 19.4 & 6.5 & 4.6 & 66.2 & 1664 & CCS \\
\hline $1 G-0.8-45 / 50$ & 31 & 93 & 3.6 & 153.6 & 23.15 & 69.6 & 6.4 & 70.8 & 2796.8 & $\mathrm{CC}$ \\
\hline $1 G-0.5-45 / 50$ & 29 & 102 & 4.3 & 143.14 & 16.189 & 58.1 & 3.8 & 69.0 & 1797.7 & CCS \\
\hline $1 G-0.25-45 / 50$ & 29 & 103 & 4.6 & 128.58 & 17.17 & 42.0 & 3.7 & 68.9 & 1790.5 & EED \\
\hline $1 G-0.8-45 / 100$ & 29 & 98 & 0.4 & 145.6 & 18.8 & 60.8 & 47.0 & 68.9 & 2158.1 & CCS \\
\hline $1 G-0.5-45 / 100$ & 29 & 105 & 4.65 & 147.7 & 28.2 & 63.1 & 6.1 & 68.9 & 3517.2 & $\mathrm{CC}$ \\
\hline $1 G-0.25-45 / 100$ & 29 & 101 & 4.4 & 130.3 & 17.7 & 43.9 & 4.0 & 68.8 & 1864.4 & CCS-EC \\
\hline $1 G-0.8-45 / 150$ & 29 & 99 & 4.1 & 150.5 & 20.9 & 66.2 & 5.1 & 68.9 & 2474.2 & $\mathrm{EC}$ \\
\hline $1 G-0.5-45 / 150$ & 29 & 99 & 4.1 & 150.8 & 28.5 & 66.5 & 7.0 & 68.7 & 3606.5 & $\mathrm{CC}$ \\
\hline $1 G-0.25-45 / 150$ & 29 & 103 & 4.6 & 139.1 & 24.01 & 53.6 & 5.2 & 68.9 & 2724.2 & EED \\
\hline $2 \mathrm{G}-0.8-45 / 50$ & 33 & 104 & 4 & 180.8 & 24.11 & 99.7 & 6.0 & 70.3 & 3440.1 & CCS \\
\hline $2 \mathrm{G}-0.5-45 / 50$ & 31 & 104 & 4.1 & 172.15 & 18.37 & 90.1 & 4.5 & 70.1 & 2393.9 & CCS \\
\hline $2 G-0.25-45 / 50$ & 36 & 103 & 4.2 & 152 & 29.3 & 67.9 & 7.0 & 70.1 & 3664.9 & $\mathrm{EC}$ \\
\hline $2 G-0.8-45 / 100$ & 31 & 117 & 4.9 & 178.28 & 24.8 & 96.9 & 5.1 & 70.1 & 3563.1 & $\mathrm{CC}$ \\
\hline $2 G-0.5-45 / 100$ & 31 & 101 & 3.7 & 162.5 & 12.5 & 79.5 & 3.4 & 70.1 & 1428.7 & CCS \\
\hline $2 G-0.25-45 / 100$ & 31 & 103 & 4.3 & 141.1 & 19.7 & 55.8 & 4.6 & 71.5 & 2241.2 & $\mathrm{CC}$ \\
\hline $2 G-0.8-45 / 150$ & 34 & 101 & 4 & 176.2 & 27.2 & 94.6 & 6.8 & 68.8 & 3801.5 & CC \\
\hline $2 G-0.5-45 / 150$ & 31 & 105 & 4.1 & 166.9 & 14 & 84.3 & 3.4 & 70.1 & 1688.9 & EED \\
\hline $2 G-0.25-45 / 150$ & 31 & 100 & 3.9 & 146.9 & 18.3 & 62.2 & 4.7 & 70.0 & 2105.2 & $\mathrm{EC}$ \\
\hline $1 G-0.8-60 / 50$ & 31 & 101 & 4.4 & 150.9 & 23.2 & 66.6 & 5.3 & 70.1 & 2817.6 & $\mathrm{CC}$ \\
\hline $1 G-0.5-60 / 50$ & 30 & 104 & 4.6 & 150.6 & 23.4 & 66.3 & 5.1 & 70.0 & 2837 & CCS \\
\hline $1 G-0.25-60 / 50$ & 37 & 103 & 4.8 & 139.5 & 33.2 & 54.1 & 6.9 & 70.4 & 3966.5 & EED \\
\hline $1 G-0.8-60 / 100$ & 29 & 107 & 4.8 & 159.8 & 33.4 & 76.5 & 7.0 & 70.2 & 4403.5 & IED \\
\hline $1 G-0.5-60 / 100$ & 29 & 104 & 4.7 & 160.6 & 33.46 & 77.4 & 7.1 & 69.9 & 4382.5 & $\mathrm{CC}$ \\
\hline $1 G-0.25-60 / 100$ & 36 & 95 & 4 & 135 & 19.88 & 49.1 & 5.0 & 69.9 & 2152.1 & CCS \\
\hline $1 G-0.8-60 / 150$ & 30 & 105 & 4.6 & 154.6 & 28.6 & 70.7 & 6.2 & 70.2 & 3661 & $\mathrm{CC}$ \\
\hline $1 G-0.5-60 / 150$ & 30 & 101 & 4.2 & 146.2 & 20.9 & 61.5 & 5.0 & 70.0 & 2481.9 & CCS \\
\hline $1 G-0.25-60 / 150$ & 33 & 96 & 4.1 & 136.6 & 22.2 & 50.9 & 5.4 & 70.1 & 2478.7 & EED \\
\hline
\end{tabular}




\begin{tabular}{|c|c|c|c|c|c|c|c|c|c|c|}
\hline $2 \mathrm{G}-0.8-60 / 50$ & 32 & 108 & 4 & 175.5 & 23.7 & 93.8 & 5.9 & 71.0 & 3375.9 & CCS \\
\hline $2 G-0.5-60 / 50$ & 33 & 96 & 3.4 & 169.5 & 15.8 & 87.2 & 4.6 & 71.2 & 1975.7 & EED \\
\hline $2 \mathrm{G}-0.25-60 / 50$ & 31 & 103.8 & 4.4 & 148.1 & 30.6 & 63.6 & 7.0 & 71.1 & 3776.9 & EED \\
\hline $2 \mathrm{G}-0.8-60 / 100$ & 30 & 97 & 3.8 & 167.4 & 12.6 & 84.9 & 3.3 & 69.7 & 1460.4 & CCS \\
\hline $2 \mathrm{G}-0.5-60 / 100$ & 31 & 107 & 4.1 & 164.7 & 15.3 & 81.9 & 3.7 & 71.3 & 1881.1 & EED \\
\hline $2 G-0.25-60 / 100$ & 31 & 101 & 3.9 & 142.3 & 19.7 & 57.2 & 5.1 & 70.2 & 2287.1 & $\mathrm{SF}$ \\
\hline $2 G-0.8-60 / 150$ & 37 & 104 & 4.2 & 167.9 & 19.5 & 85.4 & 4.6 & 71.0 & 2593.5 & CCS \\
\hline $2 \mathrm{G}-0.5-60 / 150$ & 31 & 106 & 4 & 167.5 & 15.4 & 85.0 & 3.9 & 71.5 & 1933.9 & CCS \\
\hline $2 G-0.25-60 / 150$ & 31 & 107 & 4.5 & 143.9 & 24.7 & 58.9 & 5.5 & 70.8 & 2933.4 & CCS \\
\hline $1 G-0.8-90 / 50$ & 29 & 96 & 3.8 & 153.1 & 29 & 69.1 & 7.6 & 70.0 & 3646.9 & $\mathrm{CC}$ \\
\hline $1 G-0.5-90 / 50$ & 30 & 100 & 4.4 & 148.6 & 25.2 & 64.1 & 5.7 & 69.9 & 3057.1 & $\mathrm{CC}$ \\
\hline $1 G-0.25-90 / 50$ & 30 & 93 & 3.8 & 131.6 & 21.7 & 45.3 & 5.7 & 69.9 & 2345.8 & EED \\
\hline $1 G-0.8-90 / 100$ & 29 & 103 & 4.4 & 152.6 & 35.14 & 68.5 & 8.0 & 69.9 & 4528.8 & $\mathrm{CC}$ \\
\hline $1 G-0.5-90 / 100$ & 31 & 95 & 3.8 & 140.2 & 22.1 & 54.8 & 5.8 & 69.7 & 2576.6 & EED \\
\hline $1 G-0.25-90 / 100$ & 29.5 & 95 & 4 & 135.2 & 22.1 & 49.3 & 5.5 & 69.7 & 2442.8 & $\mathrm{CC}$ \\
\hline $1 G-0.8-90 / 150$ & 31 & 96 & 3.9 & 153.1 & 25.15 & 69.1 & 6.4 & 70.5 & 3123.8 & $\mathrm{CC}$ \\
\hline $1 G-0.5-90 / 150$ & 30 & 103 & 4.5 & 145.1 & 20.4 & 60.2 & 4.5 & 69.8 & 2370.7 & EED \\
\hline $1 G-0.25-90 / 150$ & 34 & 99 & 4.5 & 137.6 & 33.7 & 52.0 & 7.5 & 69.9 & 3970.7 & EED \\
\hline $2 G-0.8-90 / 50$ & 30 & 106 & 4.2 & 169.8 & 13.3 & 87.5 & 3.2 & 70.2 & 1533.6 & $\mathrm{CC}$ \\
\hline $2 \mathrm{G}-0.5-90 / 50$ & 31 & 100.1 & 3.8 & 168.6 & 15.75 & 86.2 & 4.1 & 70.3 & 1932.2 & CCS \\
\hline $2 \mathrm{G}-0.25-90 / 50$ & 30 & 104 & 4.6 & 145.4 & 34 & 60.6 & 7.4 & 70.0 & 4131.2 & CCS \\
\hline $2 \mathrm{G}-0.8-90 / 100$ & 34 & 103 & 4.2 & 165.6 & 13.5 & 82.9 & 3.2 & 68.8 & 1559.9 & $\mathrm{CC}$ \\
\hline $2 G-0.5-90 / 100$ & 33 & 105 & 4.45 & 156.24 & 14.3 & 72.5 & 3.2 & 68.7 & 1631.5 & CCS \\
\hline $2 \mathrm{G}-0.25-90 / 100$ & 35 & 105 & 4.4 & 141.4 & 31 & 56.2 & 7.0 & 69.6 & 3734 & CCS \\
\hline 2G-0.8-90/150 & 33 & 99 & 3.6 & 168.3 & 16.5 & 85.9 & 4.6 & 70.0 & 2077.2 & IED \\
\hline $2 \mathrm{G}-0.5-90 / 150$ & 29 & 95 & 3.7 & 165 & 17.3 & 82.2 & 4.7 & 70.0 & 2142.8 & CCS \\
\hline $2 G-0.25-90 / 150$ & 31 & 101 & 4.2 & 144.6 & 16.9 & 59.7 & 4.0 & 69.1 & 1774.8 & EED \\
\hline
\end{tabular}

$P_{\mathrm{cr}}=$ load at cracking, $P_{\mathrm{y}}$ and $\Delta_{\mathrm{y}}=$ load and deflection at yielding, $P_{\mathrm{u}}$ and $\Delta_{\mathrm{u}}=$ load and deflection at ultimate, $P_{\mathrm{u}} \%$ is the percentage increase in the load carrying capacity, $\mu=$ ductility index, $E=$ stiffness, $\Omega=$ energy absorption (area under P- $\Delta$ curve).

CC concrete crushing, CCS concrete cover separation, EED end epoxy debonding, EC epoxy crushing, IED Intermediate epoxy debonding and SF shear failure.

Table 2: FE analysis from ANSYS results and failure modes of the beams.

\section{Effect of NSM Bar Length}

The effect of the NSM bar length on the flexural behavior of strengthened beams was investigated in this section. (Fig. 9) shows load deflection curves, mid-span steel strain and mid span FRP bars strain for different beams, the bars length were $0.8,0.5$ and 0.25 of the beam span; 1600,1000 , and $500 \mathrm{~mm}$.

It is clear from (Fig. 9-a) that increasing of the NSM bar length played a significant effect in increasing the ultimate load carrying capacity, similar result was reported in [8, 19 and 25]. The load carrying capacity for beams 2G-0.8-150/90, 2G$0.5-150 / 90$ and $2 \mathrm{G}-0.25-150 / 90$ were $168.3,165$ and $130.9 \mathrm{kN}$ with increasing of $85.9,82.2$ and $44.6 \%$ respectively if compared with CB. A small noticeable enhancement in load carrying capacity between beams strengthened with NSM bar length $0.8 \mathrm{~L}$ and $0.5 \mathrm{~L}$ which was $2 \%$, this may be due to the covering of the constant moment region with the bar length of 0.5L unlike the beam strengthened with FRP bar of length $0.8 \mathrm{~L}$ which extended outside the constant moment region which lead to a little effect in increasing the load carrying capacity over beam strengthened with 0.5L bar length. The same observation in the NSM FRP load strain curve see (Fig. 9-c). 


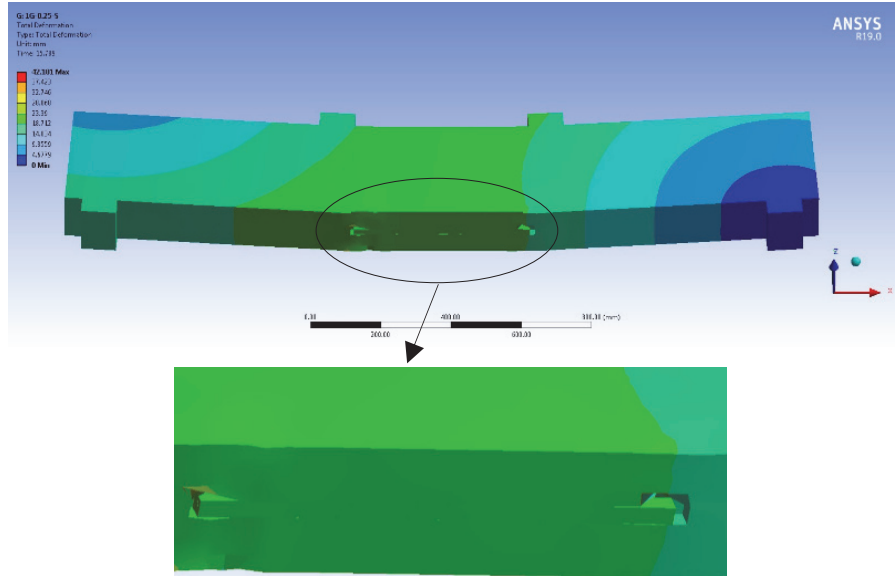

(a)

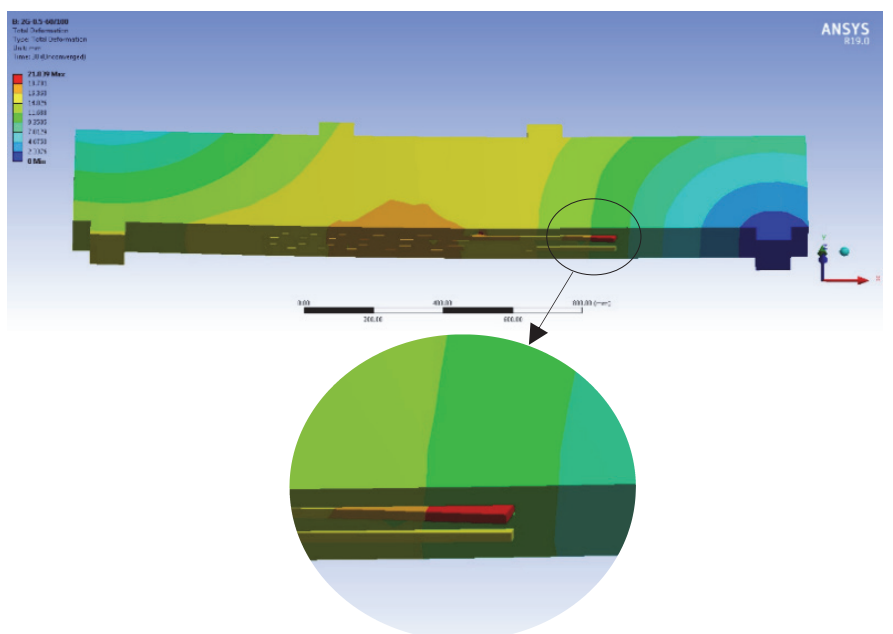

(c)

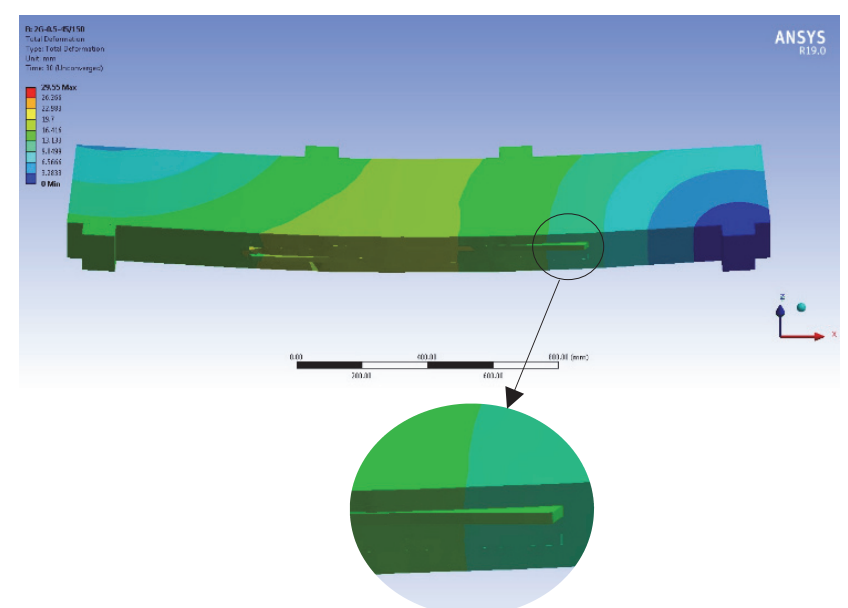

(b)

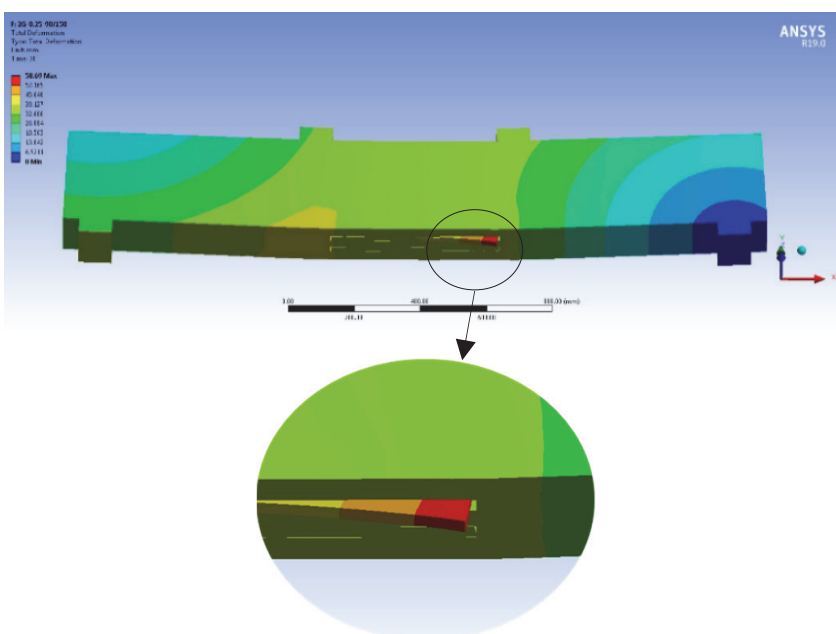

(d)

Figure 7: Failure modes of the beams: (a) 1G-0.25/S, (b) 2G-0.5-45/150, (c) 2G-0.5-60/100 and (d) 2G-0.25-90/150.

(Fig. 8) shows the predicted crack patterns from the FE analysis at failure for CB and strengthened beams; 2G-0.5-S, 2G$0.25-\mathrm{S}$ and $1 \mathrm{G}-0.25-\mathrm{S}$.

(Fig. 10) shows the effect of NSM bar length for the strengthened beams on load carrying capacity with respect to load carrying capacity of the corresponding beam but without end anchorage $P_{\mathrm{u}} / P_{\mathrm{u}, \theta=0}$, noticeable enhancement (and close together) in all beams strengthened with one NSM FRP bar when use NSM bar length of $0.5 \mathrm{~L}$ and $0.8 \mathrm{~L}$ if compared with the same beam but without end anchorage see (Fig 10-a), greater improvement in load carrying capacity when use one NSM bar of length $0.25 \mathrm{~L}$ with respect to the same beam without end anchorage, the big improvement reflect the great effect of the end anchorage in small NSM bars length. Beam strengthened with two NSM bars shown in (Fig 10-b), the figure confirm that the efficiency of the end anchorage increase with the decrease of the NSM bar length from length $0.8 \mathrm{~L}$ to length $0.25 \mathrm{~L}$, there are noticeable enhancement in load carrying capacity when use NSM bar length of $0.5 \mathrm{~L}$ if compared with $0.8 \mathrm{~L}$. The load carrying capacity of beams strengthened with same NSM bar length gives close results even though they had different parameters such as end inclination angle and end inclination leg length, this mean that the bar length is the main factor controlling the increasing of load carrying capacity of strengthened beams. 


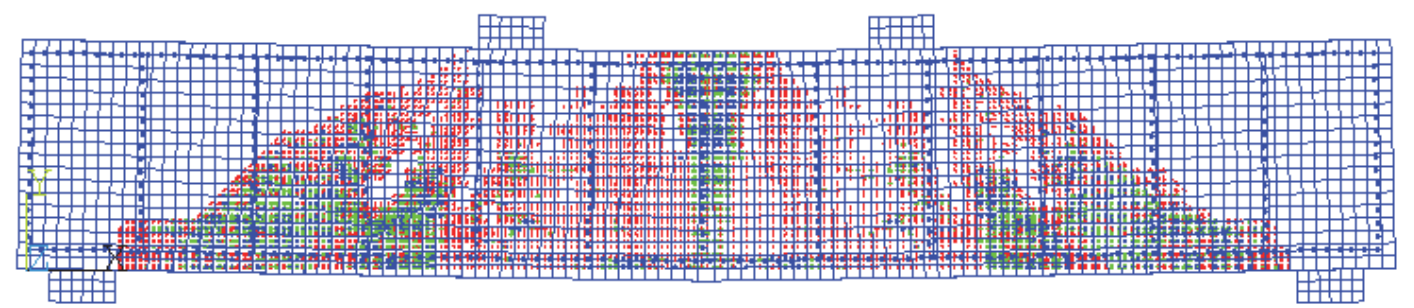

(a)

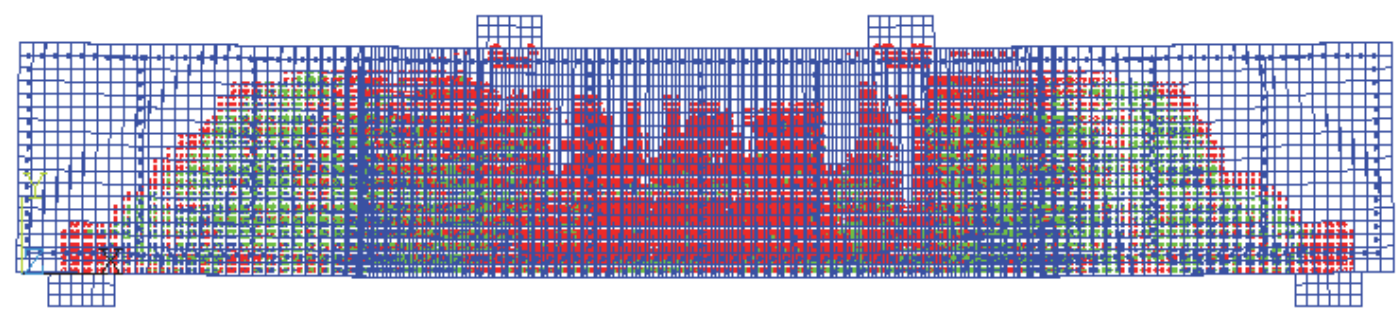

(b)

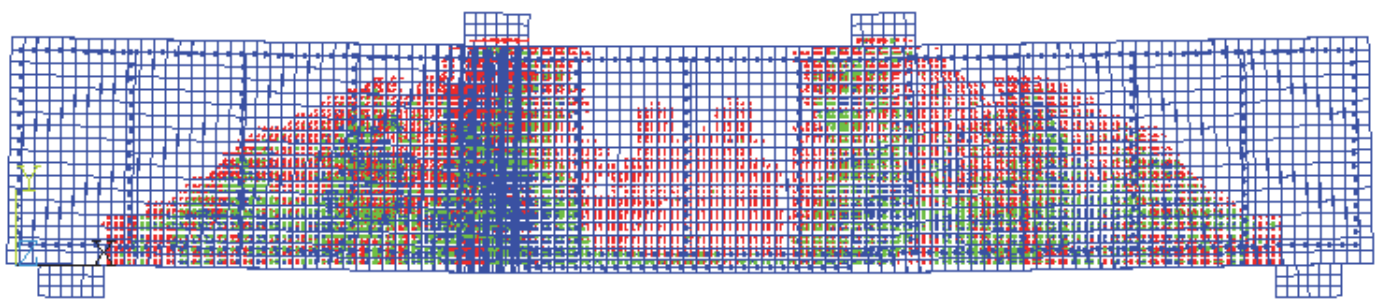

(c)

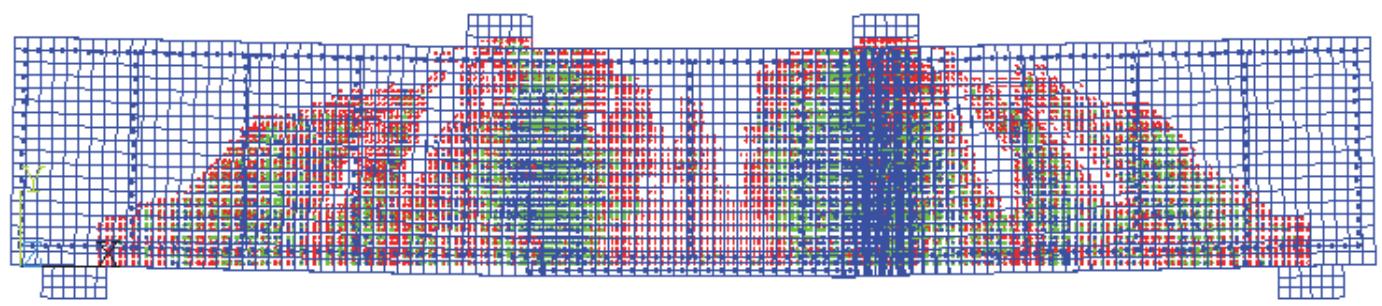

(d)

Figure 8: Predicted crack patterns of the beams at failure: (a) CB, (b) 2G-0.5-S, (c) 2G-0.25-S and (d) 1G-0.25-S.
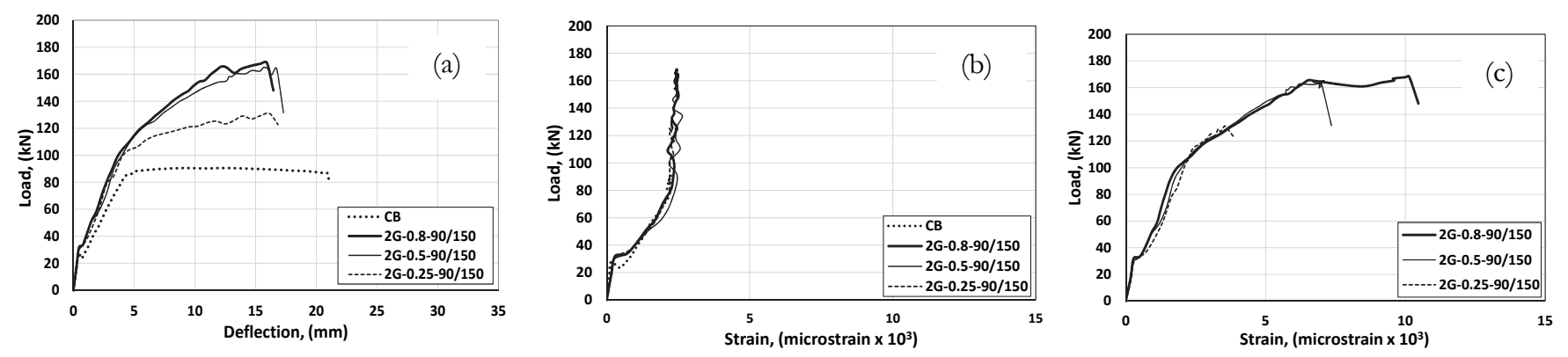

Figure 9: Effect of NSM bar length: (a) load-deflection curve, (b) steel strain and (c) FRP strain. 

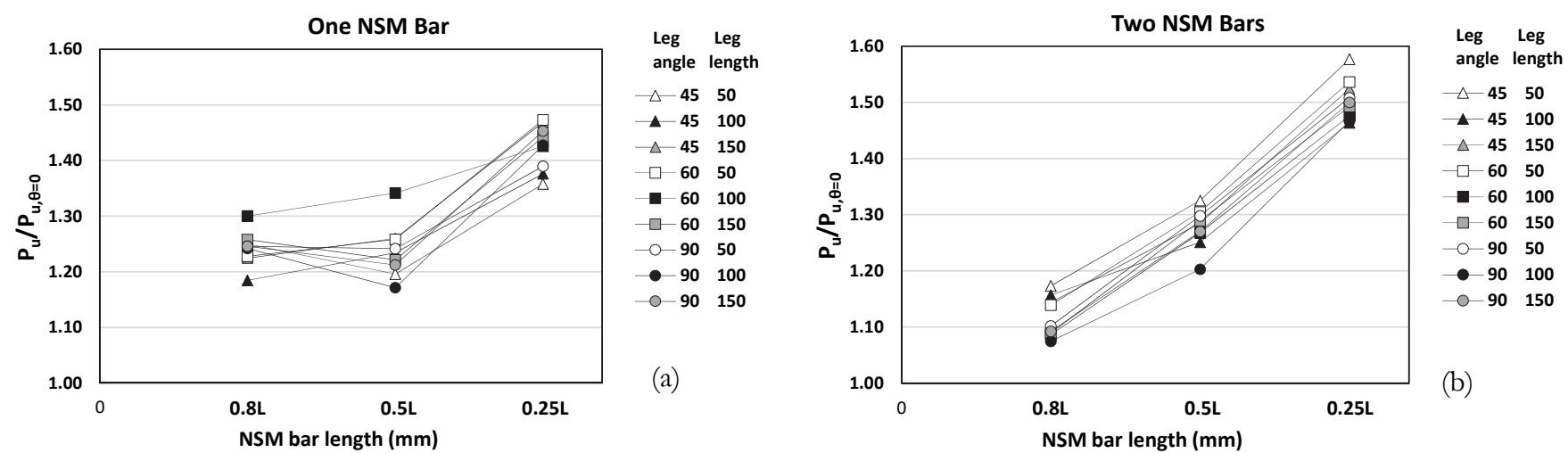

Figure 10: The effect of NSM bar length on $P_{\mathrm{u}} / P_{\mathrm{u}, \theta=0}$ for: (a) beams strengthened with one NSM bar and (b) beams strengthened with two NSM bars.
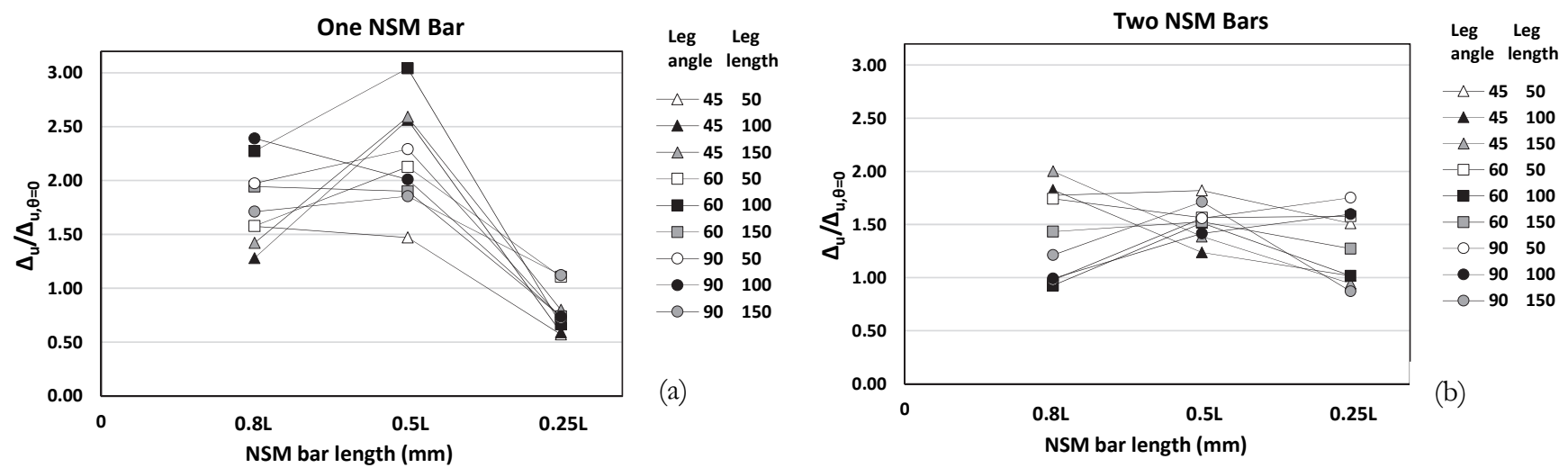

Figure 11: The effect of NSM bar length on $\Delta_{\mathrm{u}} / \Delta_{\mathrm{u}, \theta=0}$ for: (a) beams strengthened with one NSM bar and (b) beams strengthened with two NSM bars.
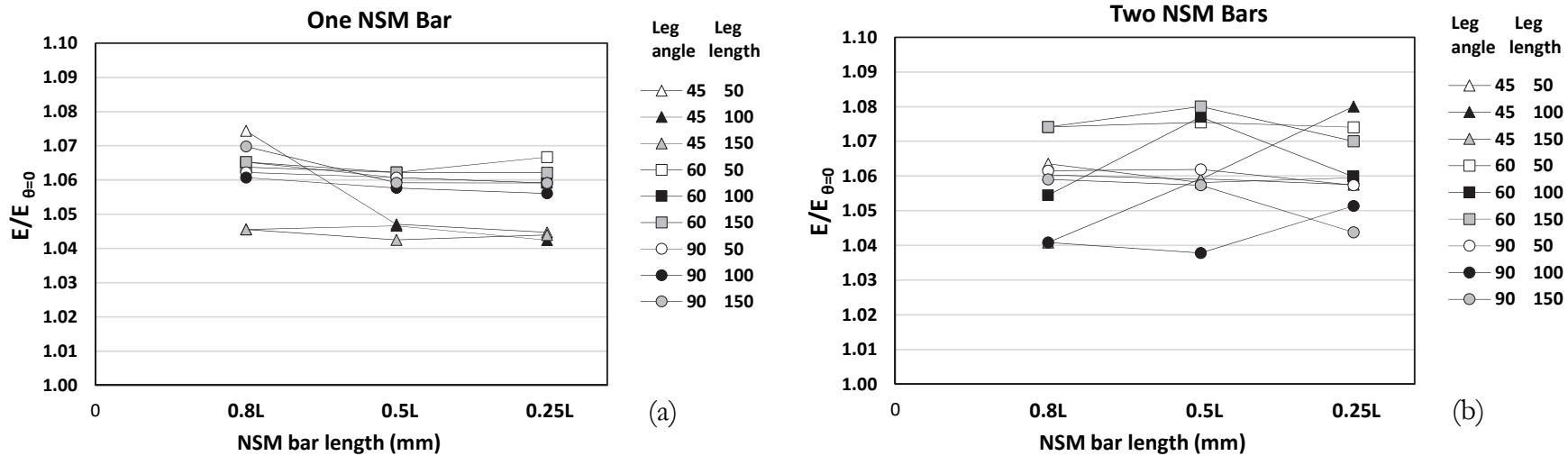

Higure 12: 'I 'he effect of NSM bar length on $E / E_{\theta=0}$ for: (a) beams strengthened with one NSM bar and (b) beams strengthened with two NSM bars.

The effect of NSM bar length for the strengthened beams on maximum deflection with respect to maximum deflection of the corresponding beam but without end anchorage $\Delta_{\mathrm{u}} / \Delta_{\mathrm{u}, \theta=0}$ were shown in (Fig. 11), the highest increasing in maximum deflection were for beam strengthened with one NSM bar of length 0.5L see (Fig. 11-a). The same observation in beams strengthened with two NSM bars with end inclination angle $60^{\circ}$ and $90^{\circ}$ see (Fig. 11-b). (Fig. 12) shows the effect of NSM bar length on the beams stiffness compared to the stiffness of the corresponding beams but without end anchorage $E / E_{\theta}=0$, there are no noticeable changes in the stiffness of beams strengthened with one NSM bar when use different NSM bar length $0.8 \mathrm{~L}, 0.5 \mathrm{~L}$ and $0.25 \mathrm{~L}$ see Fig (12-a). 
Effect of NSM Bar Number

The effect of the NSM FRP bar number was shown in (Fig. 13), the figure clarify that the increasing of bar number in the strengthened beams from one bar to two bars increase the load carrying capacity of the strengthened beams, the load carrying capacity for beams $2 \mathrm{G}-0.5-50 / 90$ and $1 \mathrm{G}-0.5-50 / 90$ were 168.6 and $148.6 \mathrm{kN}$ with increasing of 86.2 and $64.1 \%$ respectively if compared with $\mathrm{CB}$, using two bars instead of one bar increase the load carrying capacity by $13.5 \%$, this result agree with this reported in [11], (Fig13-c) shows the same observation for the effect of NSM bar length on the strain of NSM FRP bars.
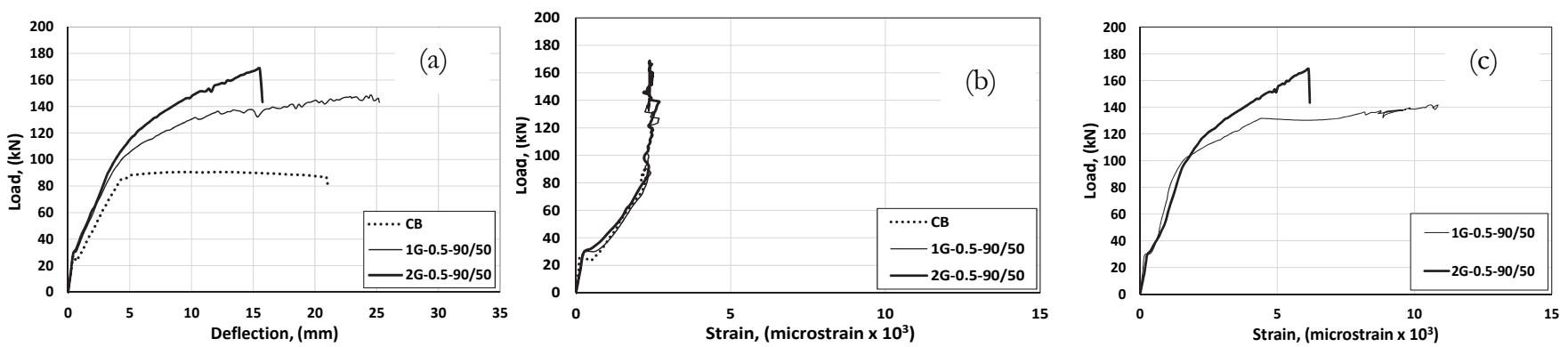

Figure 13: Effect of NSM bar number: (a) load-deflection curve, (b) steel strain and (c) FRP strain.
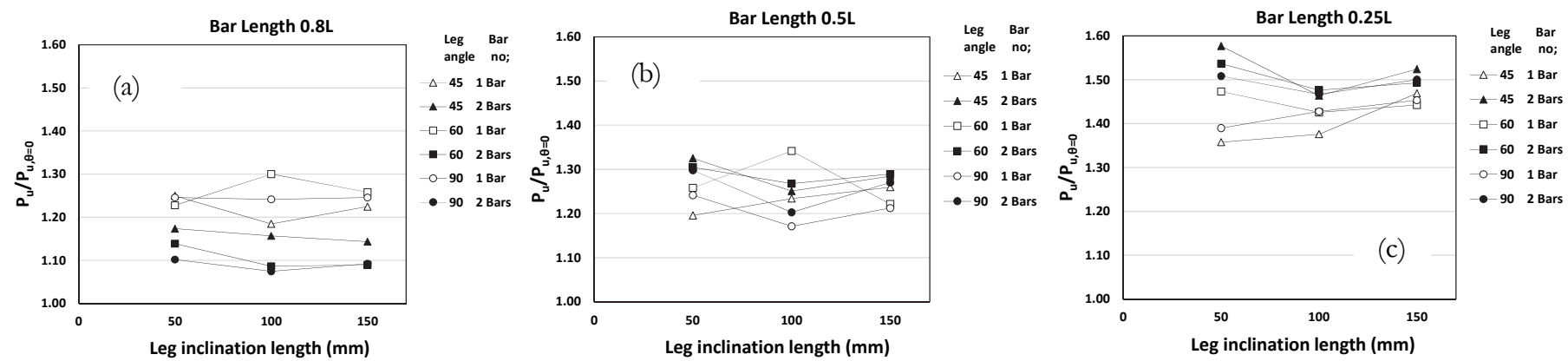

Figure 14: The effect of NSM bar number on $P_{\mathrm{u}} / P_{\mathrm{u}, \theta=0}$ for: (a) beams strengthened with bar length 0.8L, (b) beams strengthened with bar length $0.5 \mathrm{~L}$ and $(\mathrm{c})$ beams strengthened with bar length $0.25 \mathrm{~L}$.
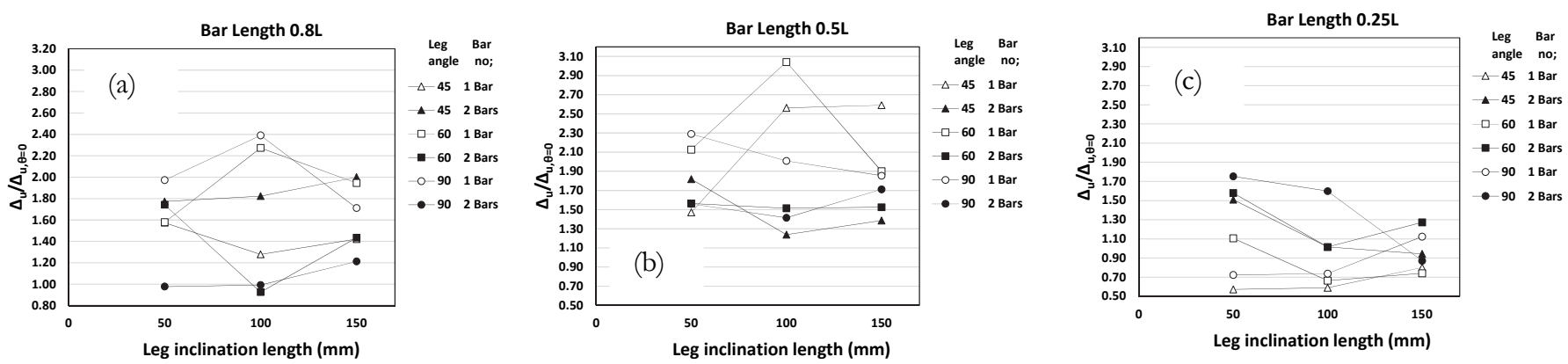

Figure 15: The effect of NSM bar number on $\Delta_{\mathrm{u}} / \Delta_{\mathrm{u}, \theta=0}$ for: (a) beams strengthened with bar length 0.8L, (b) beams strengthened with bar length $0.5 \mathrm{~L}$ and $(\mathrm{c})$ beams strengthened with bar length $0.25 \mathrm{~L}$.
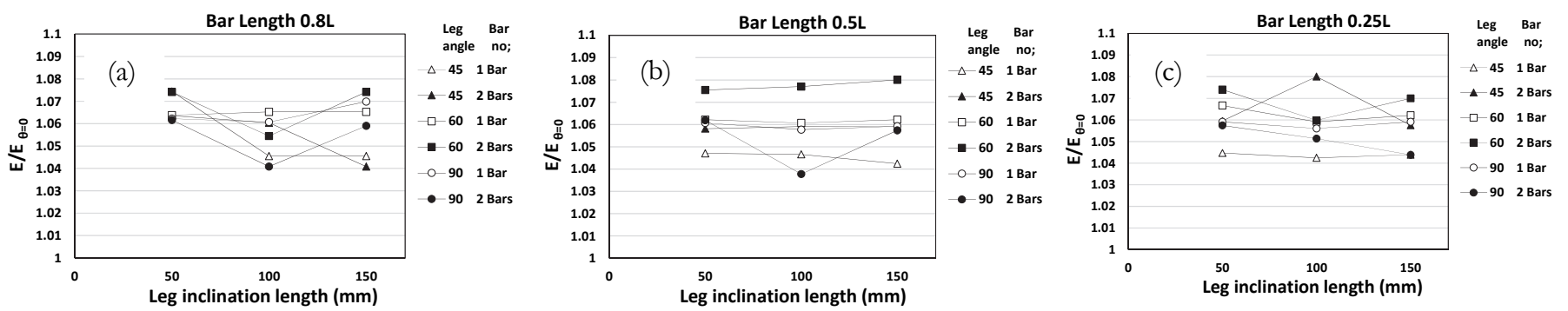

Figure 16: The effect of NSM bar number on $E / E_{\theta=0}$ for: (a) beams strengthened with bar length $0.8 \mathrm{~L}$, (b) beams strengthened with bar length $0.5 \mathrm{~L}$ and (c) beams strengthened with bar length $0.25 \mathrm{~L}$. 
The effect of the NSM FRP bar number for the strengthened beams on load carrying capacity with respect to load carrying capacity the corresponding beam but without end anchorage $P_{\mathrm{u}} / P_{\mathrm{u}, \theta=0}$ were shown in (Fig. 14), the beams strengthened with one NSM FRP bar gives higher enhancement compared to the beams strengthened with two NSM FRP bars in case of strengthening with NSM bar length of $0.8 \mathrm{~L}$, this may be because of the large confinement of the NSM bar compared to two bars show (Fig. 14-a). Unlike beams strengthened with two bars of length 0.5L and 0.25L gives more enhancement over beams strengthened with one NSM bar as shown in (Fig. 14-b and c), this may be due to the occurrence of the full length of the NSM bars in the maximum moment region which made it more effective, and the increasing of the bars number leads to increasing the load carrying capacity. The stiffness of the strengthened beams give the same trend of load carrying capacity see (Fig. 16).

\section{Effect of End Anchorage Inclination Angle}

In this section the effect of end anchorage inclination angle on the flexural response for CB, 2G-0.5/S, 2G-0.5-45/50, 2G$0.5-60 / 50$ and 2G-0.5-90/50 beams are shown in (Fig. 17). In general beams strengthened with NSM FRP having end anchorage inclined by $45^{\circ}$ gives higher load carrying capacity compared to those beams strengthened with NSM FRP having end anchorage inclined by $60^{\circ}, 90^{\circ}$ and others with straight bars that may be due to enhancement of the shear capacity of the strengthened beams, the same result was reported in [8,24], beams strengthened with end inclination angle of $60^{\circ}$ gives load carrying capacity close to beams strengthened with end inclination angle of $90^{\circ}$, as shown in (Fig. 17-a); beam 2G-0.5$45 / 50$ with inclination angle of $45^{\circ}$ gives the highest load carrying capacity $172.15 \mathrm{kN}$ which increased by $90.1 \%$ if compared with CB. The next 2G-0.5-60/50 beam with inclination angle of $60^{\circ}$ gives $169.5 \mathrm{kN}$ with increase of $87.2 \%$ if compared with CB, beam 2G-0.5-90/50 with inclination angle of $90^{\circ}$ gives $168.6 \mathrm{kN}$ with increase of $86.2 \%$ if compared with CB. The lower increase in load carrying capacity was in beam $2 \mathrm{G}-0.5 / \mathrm{S}$ with straight end which gives $129.9 \mathrm{kN}$ with $43.5 \%$ enhancement when compared with CB.
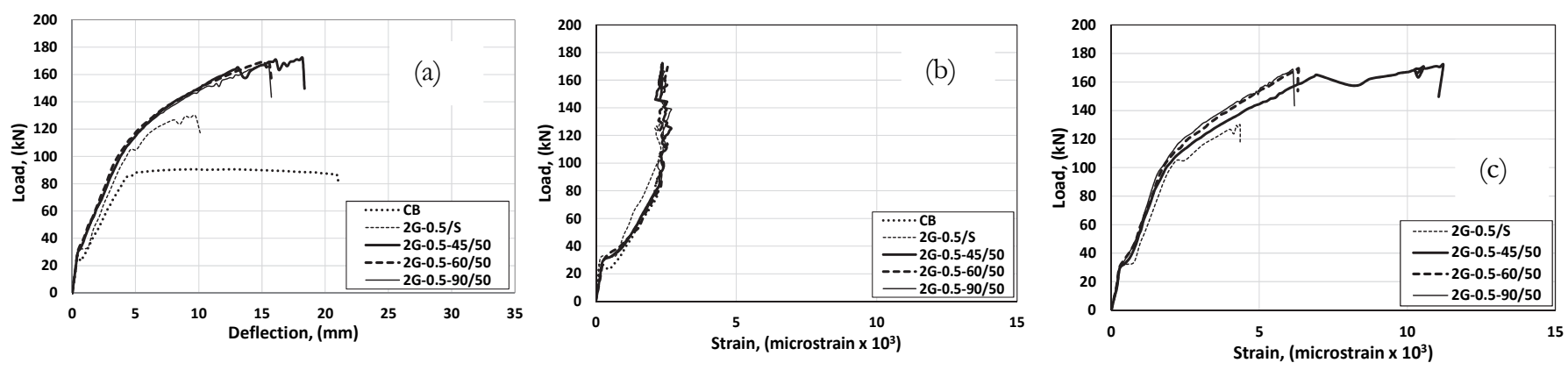

Figure 17: The effect of end anchorage inclination angle: (a) load-deflection curve, (b) steel strain and (c) FRP strain.

The effect of end anchorage inclination angle on maximum load carrying capacity $P_{\mathrm{u}}$, maximum deflection $\Delta_{\mathrm{u}}$ and stiffness E for the strengthened beams with respect to corresponding beam without end anchorage were shown in (Figs. 18, 19 and 20). From (Fig. 18) it is very clear that the beam strengthened with end anchorage inclination angle of $45^{\circ}$ gives highest enhancement in load carrying capacity if compared with beam strengthened with end anchorage inclination angle of $60^{\circ}$ and $90^{\circ}$ in cases of using two NSM bars see (Fig. 18-b) and lowest enhancement in beam stiffness in beam strengthened with one NSM bar. While the large enhancement in beam stiffness in beams strengthened with two NSM bars and end anchorage inclination angle of $60^{\circ}$ as shown in (Fig. 20-b).

Beams strengthened with end anchorage inclination angle of $90^{\circ}$ gives the lowest load carrying capacity if compared with beams strengthened with end anchorage inclination angle of $45^{\circ}$ and $60^{\circ}$ as shown in (Fig.18).

\section{Effect of End Anchorage Leg Length}

The effect of the NSM FRP end anchorage leg length on the flexural behavior of beams was shown in (Figs. 18 to 21), the figures presents a comparison between different beams with the same NSM FRP bar numbers, bar length and end anchorage inclination angle, the difference was in end anchorage length 50,100 and $150 \mathrm{~mm}$. As shown in the (Fig. 21) beams strengthened with end anchorage length of 50 and $150 \mathrm{~mm}$ gives nearly the same load carrying capacity and highest than beams strengthened with end anchorage length of $100 \mathrm{~mm}$. 

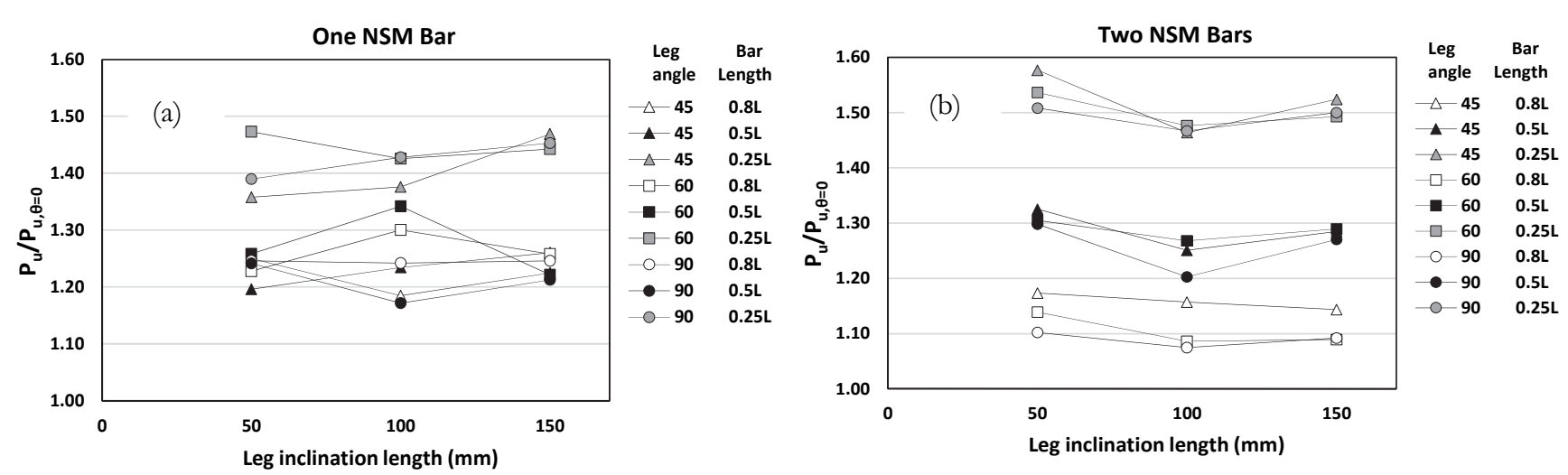

Figure 18: The effect of end anchorage inclination angle and length on $P_{\mathrm{u}} / P_{\mathrm{u}, \theta=0}$ for: (a) beams strengthened with one NSM bar and (b) beams strengthened with two NSM bars.
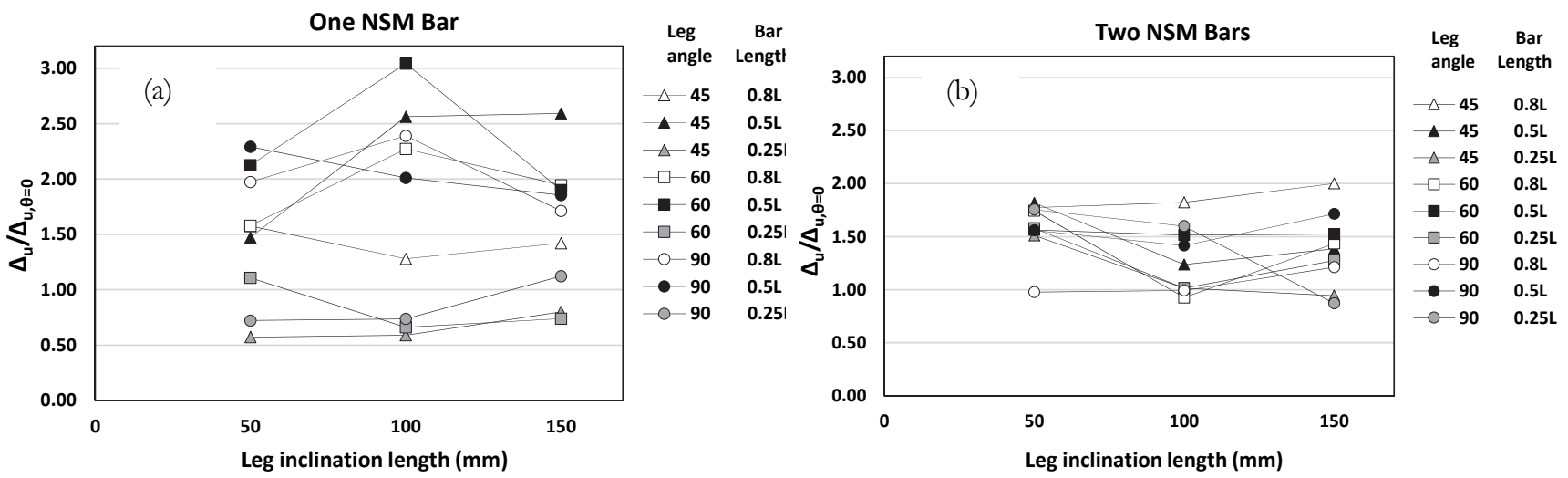

Figure 19: The effect of end anchorage inclination angle and length on $\Delta_{\mathrm{u}} / \Delta_{\mathrm{u}, \theta=0}$ for: (a) beams strengthened with one NSM bar and (b) beams strengthened with two NSM bars.
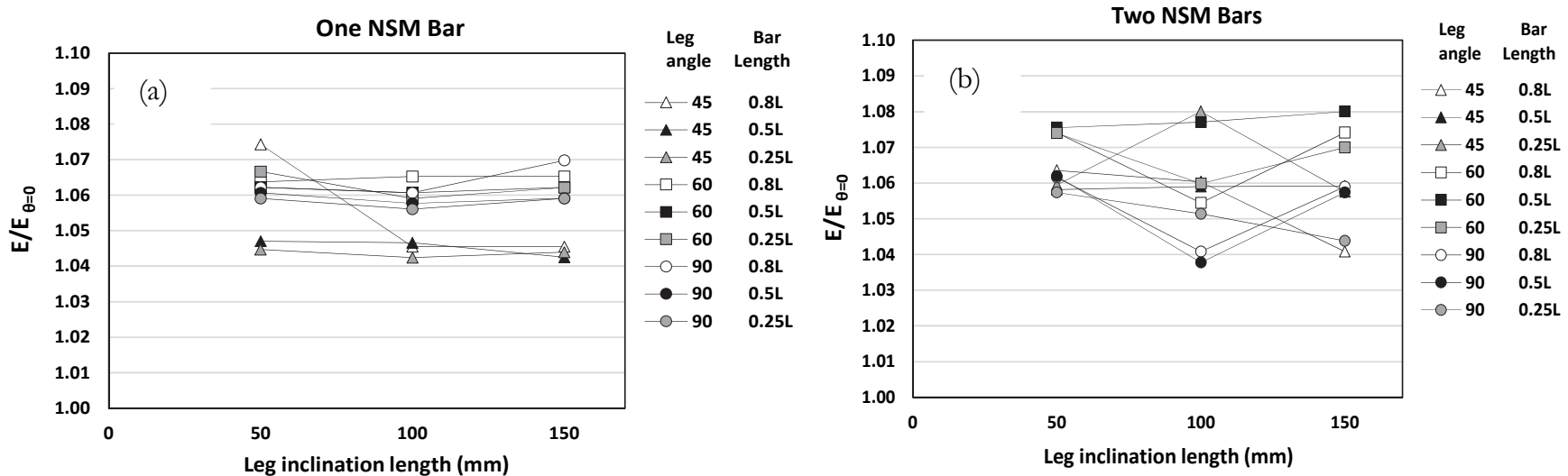

Figure 20: The effect of end anchorage inclination angle and length on $E / E_{\theta=0}$ for: (a) beams strengthened with one NSM bar and (b) beams strengthened with two NSM bars.
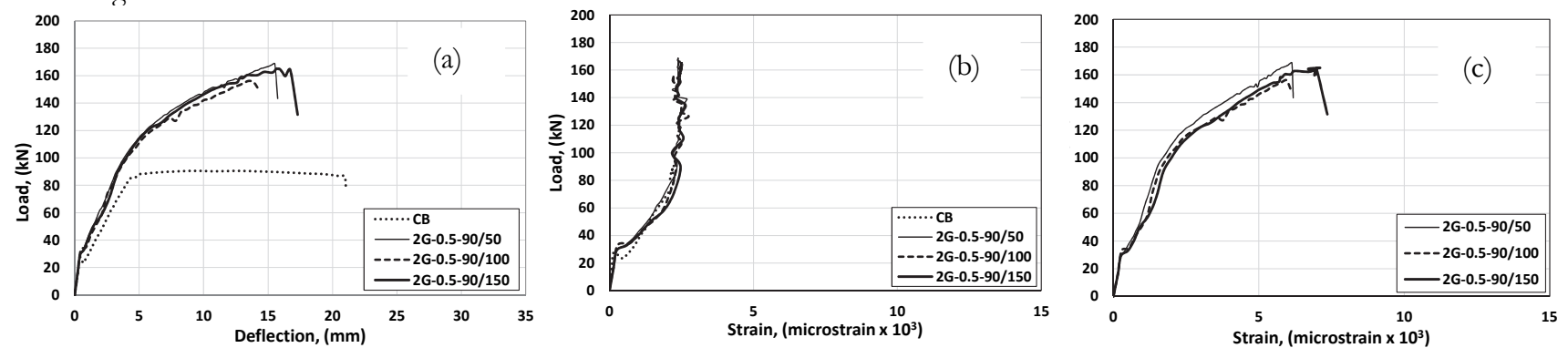

Figure 21: The effect of end anchorage length: (a) load-deflection curve, (b) steel strain and (c) FRP strain. 
Beam strengthened with end inclination leg of length $0.25 \mathrm{~L}$ gives the highest enhancement in term of load carrying capacity if compared to same beam without leg in beams strengthened with both one and two NSM FRP bars as shown in (Fig. 18$\mathrm{a}, \mathrm{b})$.

\section{CONCLUSIONS}

$\mathrm{B}$ ased on the results presented in this paper conducted from the developed FE model, the following conclusions can be drawn:

- The developed FE model is suitable for modeling and analyzing RC beams strengthened using NSM technique in flexure, and capable of predicting the different expected modes of failure.

- Increasing the NSM bar length up to $0.5 \mathrm{~L}$ has a considerable effect on the load-carrying capacity of the strengthened RC beams, while a little effect if the length increased to $0.8 \mathrm{~L}$ if compared with beams strengthened with NSM bar length $0.5 \mathrm{~L}$. - In case of strengthening with NSM bar length of $0.8 \mathrm{~L}$, the efficiency of inclined leg is more pronounced in one bar than that in two bars i.e. ( $P_{u}$ for beams strengthened by NSM with leg $/ P_{u}$ for beams strengthened by NSM without leg) in case of one bar ranged from 1.18 to 1.30 and in case of two bars ranged from 1.07 to 1.17. A different conclusion in case of using two NSM bars with length of $0.5 \mathrm{~L}$ and $0.25 \mathrm{~L}$ which gives the higher enhancement, this may be due to the occurrence of the NSM bars in the maximum moment region which made it more effective, and the increasing of the bars number leads to increasing the load carrying capacity.

- The strengthened beam with end anchorage inclined angle of $45^{\circ}$ showed superior flexural behavior in term of load carrying capacity over strengthened beam with end anchorage inclined angle of $60^{\circ}, 90^{\circ}$ and other straight.

\section{REFERENCES}

[1] Wu, Z., Wang, X. and Iwashita, K. (2007). State-of-the-Art of Advanced FRP Applications in Civil Infrastructure in Japan, Composites \& Polycon, American Composites Manufacturers Association, Tampa, FL USA, pp. 1-13.

[2] Lorenzis, L.D. and Teng, J.G. (2007). Near-surface Mounted FRP Reinforcement: An Emerging Technique for Strengthening Structures, Composites Part B, 38, pp.119-143.

[3] Laraba, A., Merdas, A. and Chikh, N. (2014). Structural Performance of RC Beams Strengthened with NSM-CFRP, Proceedings of the World Congress on Engineering, II, pp. 958-966.

[4] Bilotta, A., Ceroni, F., Nigro, E. and Pecce, M. (2015). Efficiency of GFRP NSM strips and EBR plates for flexural strengthening of RC beams and loading pattern influence, Composites Structures, 124, pp. 163-175.

[5] American Concrete Institute ACI 440. (2017). Guide for the design and construction of externally bonded FRP systems for strengthening concrete structures. MI, USA: Farmington Hills; (ACI 440.2R-17).

[6] Zhang, S.S., Yu, T. and Chen, G.M. (2017). Reinforced concrete beams strengthened in flexure with near-surface mounted (NSM) CFRP strips: Current Status and Research needs, Composites Part B, 131, pp. 30-42.

[7] Zhang, S.S. (2018). Bond strength model for near-surface mounted (NSM) FRP bonded joints: Effect of concrete edge distance, Composite Structures, 201, pp. 664-675.

[8] Reda, R.M., Sharaky, I.A., Ghanem, M., Seleem, M.H. and Sallam, H.E.M. (2016). Flexural behavior of RC beams strengthened by NSM GFRP Bars having different end conditions, Composite Structures, 147, pp. 131-142.

[9] Sharaky, I.A., Torres, L. and Sallam, H.E.M. (2015). Experimental and analytical investigation into the flexural performance of RC beams with partially and fully bonded NSM FRP bars/strips, Composite Structure, 122, pp. 113126.

[10] Sallam, H.E.M., Saba, A.M., Shaheen, H.H. and Abdel-Raouf, H. (2004). Prevention of peeling failure in plated beams, J Adv Concr Technolo, JCI, 2(3), pp. 419-429.

[11] Sharaky, I.A., Torres, L., Comas, J. and Barris, C. (2014). Flexural response of reinforced concrete (RC) beams strengthened with near surface mounted (NSM) fibre reinforced polymer (FRP) bars, Composite Structures, 109, pp. $8-22$.

[12] Parretti, R. and Nanni, A. (2004). Strengthening of RC members using near-surface mounted FRP composites: design overview, Advances in Structural Engineering, 7(6), pp. 469-483.

[13] Hassan, T. and Rizkalla, S. (2004). Bond mechanism of near surface mounted fibre reinforced polymer bars for flexural strengthening of concrete structures, ACI Structure Journal, 101(6), pp. 830-839. 
[14] Al Mahmoud, F., Castel, A., François, R. and Tourneur, C. (2009). Strengthening of RC members with near-surface mounted CFRP rods, Composite Structure, 91(2), pp. 138-147.

[15] Pereira, S. S. R., Carvalho, H., Dias, J. V. F., Verga M, V. R. and Montenegro, P. A. (2019). Behaviour of precast reinforced concrete columns subjected to monotonic short-term loading. Frattura ed Integrita Strutturale, 13(50), 242250. DOI: 10.3221 /IGF-ESIS.50.20.

[16] Dias, J. V. F., Oliveira, J. P. S., Calenzani, A. F. G. and Fakury, R. H. (2019). Elastic critical moment of lateral-distortional buckling of steel-concrete composite beams under uniform hogging moment. International Journal of Structural Stability and Dynamics, 19(7). DOI: 10.1142/S021945541950079.

[17] Santos, L. R. D., Cardoso, H. D. S., Caldas, R. B. and Grilo, L. F. (2020). Finite element model for bolted shear connectors in concrete-filled steel tubular columns. Engineering Structures, 203. doi:10.1016/j.engstruct.2019.109863.

[18] Hawileh, R.A. (2012). Nonlinear finite element modeling of RC beams strengthened with NSM FRP rods, Construction and Building Materials, 27, pp. 461-471.

[19] EL-Emam, H., El-Sisi, A., Reda, R.M., Seleem, M.H. and Bneni, M. (2020). Effect of concrete cover thickness and main reinforcement ratio on flexural behavior of RC beams strengthened by NSM-GFRP bars, Frattura ed Integrità Strutturale, 52, pp.197-210. DOI: 10.3221/IGF-ESIS.52.16.

[20] Sharaky, I.A., Selmy, S.A.I., El-Attar and M.M., Sallam, H.E.M. (2020). The influence of interaction between NSM and internal reinforcements on the structural behavior of upgrading RC beams, Composite Structures, 234-111751.

[21] ANSYS, Inc. (2018). Release 19.0 Documentation for Ansys.

[22] Hawileh, R.A., Rahman, A. and Tabatabai, H. (2010). Nonlinear finite element analysis and modeling of a precast hybrid beam-column connection subjected to cyclic loads, Applied Mathematical Modelling, 34, pp. 2562-2583.

[23] Yan, F. and Lin, Z. (2016). Bond behavior of GFRP bar-concrete interface: damage evolution assessment and FE simulation implementations, Composite Structures, 155, pp. 63-76.

[24] Sharaky, I.A., Reda, R.M., Ghanem, M., Seleem, M.H. and Sallam, H.E.M. (2017). Experimental and numerical study of RC beams strengthened with bottom and side NSM GFRP bars having different end conditions, Construction and Building Materials, 149, pp. 882-903.

[25] Shabana, I.S., Sharaky, I.A., Khalil, A., Hadad, H.S. and Arafa, E.M. (2018). Flexural response analysis of passive and active near surface- mounted joints: experimental and finite element analysis, Materials and Structures, 51(107), pp. 115.

[26] Omran, H.Y. and El-Hacha, R. (2012). Nonlinear 3D finite element modeling of RC beams strengthened with prestressed NSM-CFRP strips, Construction and Building Materials, 31, pp. 74-85.

[27] CEB-FIP Model Code 1990. Design code; (1993). 